Article

\title{
Multi-Time-Scale Coordinated Operation of a Combined System with Wind-Solar-Thermal-Hydro Power and Battery Units
}

\author{
Dongying Zhang, Ting Du $₫$, Hao Yin, Shiwei Xia *®D and Huiting Zhang \\ State Key Laboratory of Alternate Electrical Power System with Renewable Energy Sources, North China Electric \\ Power University, Beijing 102206, China \\ * Correspondence: s.w.xia@ncepu.edu.cn; Tel.: +86-010-61771614
}

Received: 24 July 2019; Accepted: 24 August 2019; Published: 1 September 2019

check for updates

\begin{abstract}
The grid connection of intermittent energy sources such as wind power and photovoltaic power generation brings new challenges for the economic and safe operation of renewable power systems. To address these challenges, a multi-time-scale active power coordinated operation method, consisting of day-ahead scheduling, hour-level rolling corrective scheduling, and real-time corrective scheduling, is proposed for the combined operation of wind-photovoltaic-thermal-hydro power and battery (WPTHB) to handle renewable power fluctuations. In day-ahead scheduling, the optimal power outputs of thermal power units, hydro-pumped storage units, and batteries are solved with the purpose of minimizing the total power generation cost. In hour-level rolling corrective scheduling, the power output plan of thermal power units and pumped storage units is modified to minimize the correction cost based on the on-off state of thermal power units determined in day-ahead scheduling. In real-time corrective scheduling stage, the feedback correction and rolling optimization-based model predictive control algorithm is adopted to modify the power output of thermal power units, hydro-pumped storage units, and batteries optimized in hour-level rolling correction scheduling, so as to ensure the economy of the correction plan and the static security of system operation. Finally, simulation results demonstrated that the proposed method can accurately track system power fluctuations, and ensure the economic and security operation of a multi-energy-generation system.
\end{abstract}

Keywords: multi-time-scale; wind-solar-thermal-hydro power and battery; coordinated operation; day-ahead scheduling; hour-level rolling corrective scheduling; real-time corrective scheduling

\section{Introduction}

Renewable energy sources such as wind and photovoltaic power generation have experienced explosive growth, and their natural intermittence brings new challenges for the economic and safe operation of renewable power systems. To handle uncertainties of renewable energy sources [1,2], an effective scheduling method for a multi-energy complementary generation system $[3,4]$ is pressingly needed to alleviate the volatility of renewable power generation [5].

At present, there are a few studies for the combined operation of a multiple-source power generation system [6-8]. A hybrid scheduling optimization model was proposed in [9] to manage the demand response for cascaded hydropower and wind-photovoltaic power stations. An integrated dispatch model with a multi-objective function was presented in [10] for optimizing the wind-photovoltaic-storage power generation output under generalized load fluctuations. In [11], a wind-hydro-thermal unit combination model was established for a day-ahead scheduling plan, and afterward the model was solved by variables separation and a piecewise linear strategy to manage the hydraulic production capacity curve. An optimal operation model for a large-scale 
wind-photovoltaic power generation system was established in [12] and the influence of dispatch time resolution on system operation cost was analyzed. In $[13,14]$ a statistical method was used to analyze the power output characteristics of wind-photovoltaic power and provide a solid data support for the combined system optimal operation. Authors of [15] proposed a constraint-based iterative search algorithm for the energy scheduling of a hybrid microgrid system with wind-photovoltaic and storages. The aforementioned references have focused on the combined system optimal scheduling of a single time scale with some promising results; however, they have not fully explored the complementary operation characteristics of multiple-energy sources for multiple time scale optimal scheduling.

Wind power and photovoltaic power generation are greatly affected by weather conditions, though the accuracy of renewable power prediction is difficult to be guaranteed, the error of wind-photovoltaic power prediction gradually decreases with the reduced time scale. At the same time, the power generation output characteristics of controllable power sources such as hydropower, thermal power, and energy storage are different at various time scales, and the complementary coordination among multiple energy sources could be explored for multi-time-scale coordinated optimal operation. In [16] a multi-time-scale scheduling for the combined cooling heating and power (CCHP) was proposed. Bukhsh et al. [17] solved an optimal power flow problem with the uncertainty of renewable energy power generation in two stages. The first stage determined the operation mode of the conventional power station, and the second stage relied on demand-side flexibility to search an optimal scheduling of wind-photovoltaic power. In [18], Xu et al. combined photovoltaic power plants with thermal energy storage and electric heaters to develop a daily stochastic two-stage wind-photovoltaic scheduling model in a rolling fashion manner. In [19], a multi-time-scale dispatch model of wind-thermal power was presented and the spinning reserve requirement was optimized to reduce the total power generation cost. In [20] a multi-time-scale active power scheduling model was established for wind-storage combined power generation system, and a dynamic economic dispatching algorithm was adopted to solve the model on the basis of rolling forecast for wind power. A multi-time-scale coordinated optimization model for CCHP was established in [21], and afterwards it was solved by a multi-scenario stochastic programming with a model predictive control method. Based on the idea of "multi-level coordination, step-by-step refinement", a multi-time-scale rolling scheduling model was established in [22,23] considering the uncertainties of wind-photovoltaic power generation and system demand response.

This paper proposes a multi-time-scale active power-coordinated scheduling method for combined operation of wind-photovoltaic-thermal-hydro power and battery units (WPTHB). Based on different power regulation speeds and capacity of batteries, thermal units, and hydro-pumped storage, a multi-time-scale scheduling model is designed to explore the complementary operation potential of batteries, thermal units, and hydro-pumped storage units. Comparing with a traditional scheduling model, the distinguished features of the proposed multi-time scheduling model are summarized as follows.

(1) Based on the differences in power regulation speed and regulating capacity of thermal power generators, hydro-pumped storage units, and batteries, a multi-time-scale scheduling framework composed of day-ahead scheduling, hour-level rolling correction scheduling, and real-time corrective scheduling is proposed for the coordinated operation of wind-photovoltaic-thermal-hydro power and battery units. The proposed scheduling method has fully explored the complementary operation features of multiple energy sources in different time scales and thus can effectively reduce the regulating pressure of thermal power generators.

(2) A predictive control algorithm incorporated with the rolling optimization and feedback correction is designed for the real-time corrective scheduling, which can effectively adjust the power outputs of thermal power generators, hydro-pumped storage units, and battery units in $15 \mathrm{~min}$ to ensure system operation security.

(3) Simulation results of a real park system in Guizhou demonstrate that the proposed model predictive control (MPC)-based multi-time-scale coordinated scheduling model can accurately track 
the wind-photovoltaic power load demands and improve the overall operation economic revenue and static security of the system.

The paper is organized as follows: Section 2 presents the complementary characteristic of wind-photovoltaic-thermal power generators, hydro-pumped storage units, and battery units, and the multi-time-scale general framework of the combined system is proposed in Section 3, with the corresponding multi-time-scale models detailed in Section 4. In Section 5, simulations on the multi-energy complementary demonstration park system in Guizhou validate the effectiveness of the proposed method, and a conclusion is drawn in the last section.

\section{Analysis on the Complementarity Operation of Wind-Photovoltaic-Thermal-Hydro Power and Battery Units}

Wind turbines convert wind dynamic energy into electricity, and its power generation is large at night and small at daytime due to changing wind speeds, thus it usually has an anti-peaking operation characteristic. Solar panels could only generate electricity during daytime and the greater the intensity of solar radiation, the greater the photovoltaic power output. In other words, the wind power change between day and night time is strongly affected by stochastic fluctuations, while for solar intensity it is straightforward, and wind can be often strong at night time while the sun is not out at night time; therefore, though both wind and photovoltaic power generation have high levels of volatility separately, they are strongly complementary when combined in operation in the hourly time scale, and could be combined to smooth the fluctuations of their total power generation.

Since uncertain wind power and photovoltaic power outputs result in operation security issues of power systems, it is important to timely maintain power balance by some easily controllable power regulation devices. Hydro-pumped storage units, thermal power generators, and battery units are such kinds of controllable devices, but with different control features. Thermal power units convert heat energy from fuel combustions into electric power. Since the complicated structure of boiler systems translates into large inertia blocks, the power regulation speed of thermal power units is usually slow and; therefore, thermal power units face difficulty meeting the fast response speed requirement for rapidly changing fluctuations. As a special type of hydropower generator, hydro-pumped storage has two-way power adjustment capability, in terms of pumping water to consume exceeding electricity during off-peak hours and releasing water to generate electricity during peak hours. Generally speaking, hydro-pumped storage can effectively play the role of peak-shaving and valley-filling based on its large power regulation capacity and fast power regulation speeds. Battery units currently deployed in power systems are mainly the lead acid battery, advanced $\mathrm{Zn} / \mathrm{Br}$ battery, advanced $\mathrm{Na} / \mathrm{S}$ battery, and super capacitors, etc., and they have fast power regulation speeds, by rapidly charging or discharging, but relatively small power regulation capacity. Therefore, conventional batteries are suitable for alleviating the high-frequency fluctuations of wind-photovoltaic power generation. In summary, a thermal power generator has outstanding power regulation capacity but a slow power regulation speed at the hourly level, while a pumped storage unit has smaller power regulation capacity than that of a thermal power generator, but it has a faster regulation speed at the minute level. For a battery unit, its power regulation speed is excellent at second-level but its power regulation capacity is relatively low. Therefore, the coordination and complementary operation of hydro-pumped storage units, thermal power generators, and conventional batteries should be explored in different time-scales to counterbalance the power fluctuations of wind-photovoltaic power outputs for power system operation security.

\section{General Framework for the Multi-Time-Scale Coordinated Operation of Combined System}

The proposed multi-time-scale coordinated operation framework is mainly composed of three time scales including the day-ahead schedule, the hour-level rolling corrective schedule, and the real-time corrective schedule, which will be detailed in what follows. 


\subsection{Day-Ahead Schedule for Next $24 \mathrm{~h}$}

The day-ahead schedule is executed with an interval of $1 \mathrm{~h}$ for the next $24 \mathrm{~h}$, and its objective is to minimize the power generation cost of battery-thermal-hydro-pumped storage. The power output limits, hourly ramping-up and down limits, and minimum on-off time constraints of thermal power units and hydro-pumped storage units, etc., are comprehensively considered in the model. Based on the wind-photovoltaic power load forecast data in the next $24 \mathrm{~h}$, a mixed integer linear programming (MILP) model was established and solved to obtain the on-off status and optimal hourly power output of battery-thermal-hydro-pumped storage in the next $24 \mathrm{~h}$.

\subsection{Hour-Level Rolling Correction Schedule}

The starting point is that there is the power deviation between the day-ahead scheduled power outputs of battery-thermal-hydro-pumped storage and the actual wind-photovoltaic power load in real time. In the traditional day-ahead scheduling, the power regulation burden mainly depends on thermal power units, and system power balance cannot be easily maintained due to the lack of fast power adjustment capability, which greatly affects system operation security. On the other hand, when the time scale of forecasting decreases, the wind-photovoltaic power load prediction accuracy increases. Therefore, based on the $3 \mathrm{~h}$-ahead updated wind-photovoltaic power load forecast data, exerting strengths of fast response generators can be used as a corrector to modify the day-ahead scheduling plan for gradually reducing the deviation between the day-ahead power generation plan and the system actual wind-photovoltaic power load, thus reducing the power regulation pressure on thermal power units.

In the combined WPTHB system, the hydro-pumped storage can be effectively adjusted for operating at the start and stop states at a time scale of $15 \mathrm{~min}$. Therefore, using the open-loop rolling optimization algorithm, the intra-day hourly rolling corrective schedule model could be established for power adjustment of thermal-hydro-pumped storage units. Specifically, with the premise of the fixed on-off status of thermal power units and the fixed power outputs of batteries in the day-ahead scheduling, the intra-day hourly power adjustment of thermal power generators and hydro-pumped storage units are solved based on the wind-photovoltaic power load updated $3 \mathrm{~h}$ ahead with an interval of $15 \mathrm{~min}$.

\subsection{MPC-Based Real-Time Corrective Scheduling}

Inspired by the rolling optimization and feedback correction idea of model predictive control (MPC), an MPC-based real-time corrective scheduling model is established. The objective is to achieve the minimal power generation adjustment cost and ensure that batteries approach the planned power output determined in the day-ahead scheduling. On basis of the 15-min ahead updated wind-photovoltaic power load and the actual operating state of power generation equipment, the sequential power output adjustments of battery-thermal-hydro-pumped storage are solved for the next $15 \mathrm{~min}$. Compared with the traditional real-time power correction, which is only optimized in one single time section, the proposed MPC-based real-time corrective scheduling model can optimize the power output of battery-thermal-hydro-pumped storage units in advance for $15 \mathrm{~min}$ by considering the changing tendency of wind-photovoltaic power load variations.

The proposed multi-time-scale coordinated scheduling framework for the combined WPTHB system is shown in Figure 1. 


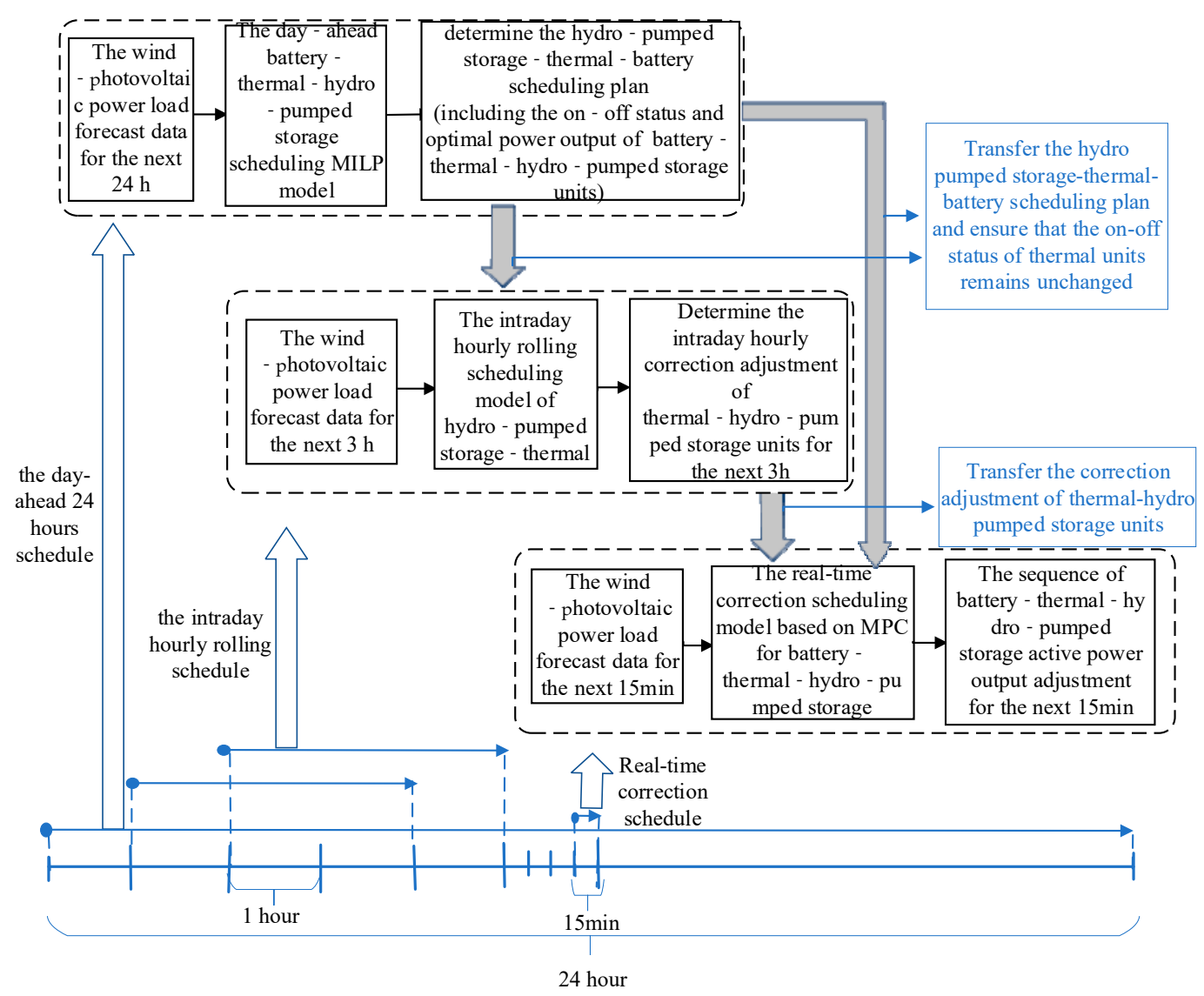

Figure 1. Multi-time-scale coordinated scheduling framework for the combined WPTHB system.

\section{Detailed Multi-Time-Scale Coordinated Operation Model for the Combined WPTHB System}

\subsection{Day-Ahead Schedule Model for Next $24 \mathrm{~h}$}

Considering network static security constraints and the day-ahead energy balance of hydro-pumped storage units and battery units, a DC power flow-based day-ahead scheduling model is developed to determine the optimal power outputs of combined WPTHB system.

a. Objective Function

The objective of day-ahead scheduling model is to minimize the combined system total generation cost. According to the forecasted wind-photovoltaic power load in the next $24 \mathrm{~h}$, the power generation cost of thermal power units, hydro-pumped storage units, and batteries is taken into account as follows:

$$
\begin{aligned}
\min F_{\text {day }}=\sum_{t=1}^{T}\left[\sum _ { i = 1 } ^ { N G } f _ { G } \left(U_{g, i}^{\text {day }}(t),\right.\right. & \left.P_{g, i}^{\text {day }}(t)\right)+\sum_{j=1}^{N H} f_{H}\left(U_{h, j}^{\text {pum,day }}(t), U_{h, j}^{\text {gen,day }}(t)\right) \\
& \left.+\sum_{l=1}^{N B} f_{B}\left(P_{b, l}^{d a y}(t)\right)\right],
\end{aligned}
$$

where $F_{d a y}$ is the total generation cost of combined system; $T$ is the number of optimization time periods; $N G$ is the number of thermal power units; $f_{G}\left(U_{g, i}^{d a y}(t), P_{g, i}^{d a y}(t)\right)$ is the power generation costs of thermal power unit $i$; $N H$ is the number of hydro-pumped storage units; $f_{H}\left(U_{h, j}^{\text {pum,day }}(t), U_{h, j}^{\text {gen,day }}(t)\right)$ is 
the power generation costs of hydro-pumped storage unit $j$; NB is the number of batteries; $f_{B}\left(P_{b, l}^{d a y}(t)\right)$ is the power generation costs of battery $l$.

$$
\begin{gathered}
f_{G}\left(U_{g, i}^{\text {day }}(t), P_{g, i}^{\text {day }}(t)\right)=a_{g, i} P_{g, i}^{\text {day }}(t)^{2}+b_{g, i} P_{g, i}^{\text {day }}(t)+c_{g, i}+S_{g, i} U_{g, i}^{\text {day }}(t)\left(1-U_{g, i}^{\text {day }}(t-1)\right), \\
f_{H}\left(U_{h, j}^{\text {pum }, \text { day }}(t), U_{h, j}^{g e n, d a y}(t)\right)=C_{h, j}^{g e n} U_{h, j}^{\text {gen,day }}(t)\left[U_{h, j}^{\text {gen, day }}(t)-U_{h, j}^{\text {gen, day }}(t-1)\right] \\
+C_{h, j}^{\text {pum }} U_{h, j}^{\text {pum,day }}(t)\left[U_{h, j}^{\text {pum }, \text { day }}(t)-U_{h, j}^{\text {pum }, \text { day }}(t-1)\right], \\
f_{B}\left(P_{b, l}^{\text {day }}(t)\right)=C_{B, l} P_{b, l}^{\text {day }}(t)^{2},
\end{gathered}
$$

where $U_{g, i}^{d a y}(t)$ is the on-off status of the thermal power unit $i$ at the $t$-th hour, 1 means on and 0 means off; $P_{g, i}^{d a y}(t)$ is active power output of the thermal power unit $i$ at the $t$-th hour; $a_{g, i}, b_{g, i}, c_{g, i}$ are generation cost coefficients of the thermal power unit $i ; S_{g, i}$ is the starting cost of the thermal power unit $i ; U_{h, j}^{\text {pum,day }}(t)$ is the water pumping state of hydro-pumped storage unit $j$ at the $t$-th hour, 1 means in the pumping state and 0 means in the non-pumping state; $U_{h, j}^{g e n, d a y}(t)$ is the power generation state of the hydro-pumped storage unit $j$ at the $t$-th hour, 1 means in the power generation state, 0 means in the non-power generation state; $C_{h, j}^{\text {gen }}$ is the starting cost for the power generation state of hydro-pumped storage unit $j ; C_{h, j}^{\text {pum }}$ is the starting cost for the pumping state of hydro-pumped storage unit $j ; C_{B, l}$ is the power generation cost coefficient of battery $l ; P_{b, l}^{d a y}(t)$ is the active power output of battery $l$ at the $t$-th hour and the positive value represents the discharging power and the negative represents the charging power.

b. Operation Constraints

The hourly ramping-up and down limits of the thermal power unit:

$$
\Delta P_{g, i, h o u r}^{-} \leq P_{g, i}^{d a y}(t)-P_{g, i}^{d a y}(t-1) \leq \Delta P_{g, i, h o u r}^{+}
$$

where $\Delta P_{g, i, h o u r}^{-}$and $\Delta P_{g, i, h o u r}^{+}$are the lower and upper ramping limits of thermal power units in $1 \mathrm{~h}$, respectively.

The power output upper and lower limits of thermal power unit:

$$
U_{g, i}^{d a y}(t) P_{g, i}^{\min } \leq P_{g, i}^{d a y}(t) \leq U_{g, i}^{d a y}(t) P_{g, i}^{\max } .
$$

The minimum on-off time constraints:

$$
\left\{\begin{array}{c}
\left(T_{g, i}^{o n, d a y}(t-1)-M T_{g, i}^{o n, d a y}\right)\left[U_{g, i}^{d a y}(t-1)-U_{g, i}^{d a y}(t)\right] \geq 0 \\
\left(T_{g, i}^{o f f, d a y}(t-1)-M T_{g, i}^{o f f, d a y}\right)\left[U_{g, i}^{d a y}(t)-U_{g, i}^{d a y}(t-1)\right] \geq 0
\end{array},\right.
$$

where $T_{g, i}^{o n, d a y}(t-1)$ is the hours of continuous "on" status of the thermal power unit $i$ until the hour $t-1 ; T_{g, i}^{o f f, d a y}(t-1)$ is the hours that the thermal power unit $i$ is continuously in the "off" status until the hour $t-1 ; M T_{g, i}^{o n, d a y}$ is the minimum "on" time in hours of the thermal power unit $i ; M T_{g, i}^{o f f, d a y}$ is the minimum "off" time in hours of the thermal power unit $i$.

The power output upper and lower limits of the hydro-pumped storage unit:

$$
P_{h, j}^{\min } \leq P_{h, j}^{d a y}(t) \leq P_{h, j}^{\max }
$$


where $P_{h, j}^{\min }$ is the maximum pumping power of the hydro-pumped storage unit $j$ (negative value); $P_{h, j}^{\max }$ is the maximum power generation of the hydro-pumped storage unit $j$ (positive value); $P_{h, j}^{d a y}(t)$ is the day-ahead power output of the pumped storage unit $j$ at the hour $t$, and the positive value represents in the power generation state, and a negative value represents in the pumping state.

Coupling constraints for water pumping and power generation state of hydro-pumped storage units:

$$
U_{h, j}^{\text {gen,day }}(t) \times U_{h, j}^{\text {pum,day }}(t)=0 .
$$

The reservoir energy balance constraint of hydro-pumped storage power station:

$$
E_{t+1}^{d a y}=E_{t}^{d a y}+\sum_{j \in H s} P_{h, j}^{d a y}(t) \times \Delta t
$$

where $E_{t}$ is the reservoir energy of hydro-pumped storage station at the $t$-th hour, $H s$ is the collection of hydro-pumped storage units contained in the hydro-pumped storage station.

The upper and lower limits of reservoir energy of the hydro-pumped storage station:

$$
E_{\min } \leq E_{t}^{d a y} \leq E_{\max }
$$

where $E_{\min }, E_{\max }$ are respectively the minimum and maximum reservoir energy of hydro-pumped storage station.

The reservoir energy of hydro-pumped storage station at the end of each day shall be ready for continuous utilizations in the next day:

$$
E_{24}^{d a y}=E_{0}
$$

where $E_{0}$ is the reservoir energy at the beginning of the day; $E_{24}$ is the reservoir energy at the end of the day under the day-ahead scheduling.

The power output upper and lower limits of the battery $l$ :

$$
P_{b, l}^{\min } \leq P_{b, l}^{d a y}(t) \leq P_{b, l}^{\max }
$$

where $P_{b, l}^{\min }, P_{b, l}^{\max }$ are, respectively, the maximum charging power (negative value) and the maximum discharging power (positive value) of the battery $l$.

The upper and lower limits of the battery energy:

$$
\left\{\begin{array}{l}
W_{b, l}^{\min } \leq W_{b, l}^{d a y}(t) \leq W_{b, l}^{\max } \\
W_{b, l}^{\text {day }}(24)=W_{b, l}^{d a y}(0) \\
W_{b, l}^{\text {day }}(\mathbf{t}+1)=W_{b, l}^{d a y}(\mathrm{t})+P_{b, l}^{\text {day }}(\mathrm{t})
\end{array}\right.
$$

where $W_{b, l}^{d a y}(t)$ is the remaining capacity of the battery $l$ at hour $t ; W_{b, l}^{\min }$ and $W_{b, l}^{\max }$ are, respectively, the minimum and the maximum energy threshold of the battery unit $l . W_{b, l}^{d a y}(0)$ is the initial energy of the battery $l$ at the beginning of the day. $W_{b, l}^{d a y}(24)$ is the remaining energy of the battery $l$ at the end of the day in the day-ahead scheduling.

Power balance constraint:

$$
P_{\text {day }, w}(t)+P_{\text {day }, v}(t)+\sum_{i=1}^{N G} P_{g, i}^{d a y}(t)+\sum_{j=1}^{N H} P_{h, j}^{d a y}(t)+\sum_{l=1}^{N B} P_{b, l}^{d a y}(t)=P_{\text {day }, \text { Load }}(t),
$$

where $P_{\text {day, }, w}(t), P_{d a y, v}(t)$, and, $P_{\text {day,Load }}(t)$ are the day-ahead forecast data of wind power, photovoltaic power, and load demand in the next $24 \mathrm{~h}$, respectively. 
System spinning reserve capacity constraint at hour $t$ :

$$
\sum_{i=1}^{N G}\left(P_{g, i}^{\max } \times U_{g, i}^{d a y}(t)\right) \geq P_{\text {day, Load }}(t)+r(t)
$$

where $r(t)$ is the system spinning reserve margin at the $t$-th hour.

Power transfer capacity constraint of transmission line:

$$
\mathrm{G}\left|\left(P_{\text {day }, w}(t), P_{\text {day }, v}(t), P_{g, i}^{d a y}(t), P_{h, j}^{d a y}(t), P_{b, l}^{d a y}(t), P_{\text {day }, \text { Load }}(t)\right)\right| \leq \overline{P_{n}}, i \in N G, j \in N H, l \in N B,
$$

where $G|(\cdot)|$ represents the transmission lines' active power flow calculated based on a DC power flow model; $\overline{P_{n}}$ is the capacity limit of $n$th transmission line.

\subsection{Hour-Level Rolling Corrective Schedule}

The hour-level rolling corrective scheduling is performed every hour, with an optimization cycle of $3 \mathrm{~h}$ and an interval of $15 \mathrm{~min}$. The corrective power of thermal generators and hydro-pumped storage units in the next $3 \mathrm{~h}$ will be optimized in this time scale.

(1) Objective of hour-level rolling corrective schedule:

$$
\min F_{\text {hours }}=\sum_{t=t_{0}+1}^{T 0}\left(\sum_{i=1}^{N G} f_{G}\left(U_{g, i}^{\text {day }}(t), P_{g, i}^{\text {hours }}(t)\right)+\sum_{j=1}^{N H}\left(U_{h, j}^{\text {gen,hours }}(t), U_{h, j}^{\text {pum, hours }}(t)\right)\right),
$$

where $F_{\text {hours }}$ is the corrective power output cost of thermal power generators and hydro-pumped storage units; $t_{0}$ is the current time point. Since the interval is $15 \mathrm{~min}$, there are 12 time periods for the next $3 \mathrm{~h}$, so $T 0=t_{0}+12 ; U_{g, i}^{\text {day }}(t)$ is the on-off state of the thermal power unit $i$ at the $t$-th time period; $P_{g, i}^{\text {hours }}(t)$ is the active power output adjustment of thermal power unit $i$ with the on-off state solved in the day-ahead scheduling; $U_{h, j}^{\text {gen,hours }}(t)$ and $U_{h, j}^{\text {pum,hours }}(t)$ are, respectively, the power generation and water pumping states of the hydro-pumped storage unit $j$ in the hour-level rolling corrective scheduling.

(2) Constraints of the hour-level rolling corrective scheduling

The ramping-up and down limits of thermal power unit in $15 \mathrm{~min}$ :

$$
\Delta P_{g, i, A}^{-} \leq P_{g, i}^{\text {hours }}(t)-P_{g, i}^{\text {hours }}(t-1) \leq \Delta P_{g, i, A^{\prime}}^{+}
$$

where $P_{g, i}^{\text {hours }}(t)$ and $P_{g, i}^{\text {hours }}(t-1)$ are the amount of active power output adjustment of the thermal power unit $i$ in the $t$-th time period and $t-1$ time period (note: each time period is $15 \min$ ); $\Delta P_{g, i, A^{\prime}}^{-}$ $\Delta P_{g, i, A}^{+}$are, respectively, the lower and the upper limits of power adjustment for thermal power unit $i$ in $15 \mathrm{~min}$.

The power output upper and lower limits of the thermal generators in $15 \mathrm{~min}$ :

$$
U_{g, i}^{\text {day }}(t) P_{g, i}^{\min } \leq P_{g, i}^{\text {hours }, 0}(t) \leq U_{g, i}^{\text {day }}(t) P_{g, i}^{\max } .
$$

The power output upper and lower limits of the hydro-pumped storage unit in $15 \mathrm{~min}$ :

$$
P_{h, j}^{\min } \leq P_{h, j}^{h o u r s, 0}(t) \leq P_{h, j}^{\max }
$$


where $P_{g, i}^{\text {hours, }}(t)$ is the sum of power output in day-ahead scheduling and the adjustment power output in hour-level rolling corrective scheduling for thermal power unit $i$, that is $P_{g, i}^{h o u r s, 0}(t)=$ $P_{g, i}^{\text {hours }}(t)+P_{g, i}^{\text {day }}(t)$; similarly, $P_{h, j}^{\text {hours }, 0}(t)$ is the sum of day-ahead scheduling power output and hour-level rolling corrective scheduling adjustment power output $P_{h, j}^{\text {hours }}(t)$ of hydro-pumped storage unit $j$, that is $P_{h, j}^{\text {hours }, 0}(t)=P_{h, j}^{\text {hours }}(t)+P_{h, j}^{\text {day }}(t)$.

Coupling constraints for water pumping and the power generation state of hydro-pumped storage unit in $15 \mathrm{~min}$ :

$$
U_{h, j}^{\text {gen,hours }}(t) \times U_{h, j}^{\text {pum,hours }}(t)=0 .
$$

The reservoir energy constraints of pumped storage station:

$$
\begin{gathered}
E_{t}^{\text {hours }}=E_{t 0}^{\text {day }}+\sum_{x=1}^{t-t 0} \sum_{j \in H s} P_{h, j}^{\text {hours }, 0}(t 0+x) \times \Delta t, \\
E_{\min } \leq E_{t}^{\text {hours }} \leq E_{\max },
\end{gathered}
$$

where $E_{t}^{\text {hours }}$ is the reservoir energy in the $t$ th 15 -min time period. $E_{t 0}^{d a y}$ is the reservoir energy at the current time point $t_{0}$ under the day-ahead scheduling. $x$ is the number of time intervals between the predicted time point and the current time point.

The constraint for continuous utilization of the hydro-pumped storage station in the next day:

$$
E_{24}^{\text {hours }}=E_{0},
$$

where $E_{0}$ is the energy reservoir at the beginning of the day; $E_{24}^{\text {hours }}$ is the reservoir energy at the end of the day in the hour-level rolling corrective scheduling.

System power balance constraints:

$$
P_{h, w}(t)+P_{h, v}(t)+\sum_{i=1}^{N G} P_{g, i}^{\text {hours }, 0}(t)+\sum_{j=1}^{N H} P_{h, j}^{\text {hours }, 0}(t)=P_{h, \text { Load }}(t),
$$

where $P_{h, w}(t), P_{h, v}(t), P_{h, \text { Load }}(t)$ are the $3 \mathrm{~h}$ ahead forecast data of wind power, photovoltaic power, and load demand, respectively.

System spinning reserve constraints in $15 \mathrm{~min}$ :

$$
\sum_{i=1}^{N G}\left(P_{g, i}^{\max } \times U_{g, i}^{d a y}(t)\right) \geq P_{h, \text { Load }}(t)+r(t),
$$

where $r(t)$ is the system spinning reserve margin for the $t$ th 15 -min time period.

Power transfer capacity limit of transmission line:

$$
\mathrm{G}\left|\left(P_{h, w}(t), P_{h, v}(t), P_{g, i}^{\text {hours }, 0}(t), P_{h, j}^{\text {hours }, 0}(t), P_{h, \text { Load }}(t)\right)\right| \leq \overline{P_{n}}, i \in N G, j \in N H,
$$

where $G|(\cdot)|$ represents the power flow of transmission lines calculated based on the DC power flow model.

\subsection{Real-Time Corrective Scheduling}

The real-time corrective scheduling utilizes the feedback and rolling optimization of model predictive control (MPC) to accurately track the wind-photovoltaic power load demand. Based on the updated wind-photovoltaic power load forecast data in the next $15 \mathrm{~min}$ and the real-time actual 
power output of thermal power units, hydro-pumped storage units, and batteries; power adjustments of thermal power units, hydro-pumped storage units, and batteries are optimized for tracking load fluctuations in the next $15 \mathrm{~min}$.

The proposed MPC-based real-time corrective scheduling model is composed of the following general steps: (1) Select the state variables $X_{t}=\left[P_{g, i}(t), P_{h, j}(t), P_{b, l}(t), W_{b, l}(t)\right], i \in N G, j \in N H, l \in N B$, which include the active power outputs of thermal power units, hydro-pumped storage units, and batteries, and the remaining energy of batteries; select the real-time power adjustment of thermal power units, hydro-pumped storage units, and batteries as the control variable $\Delta U_{t}, \Delta U_{t}=$ $\left[\Delta P_{g, i}(t), \Delta P_{h, j}(t), \Delta P_{b, l}(t)\right], i \in N G, j \in N H, l \in N B$. The real-time corrective scheduling is performed every $5 \mathrm{~min}$ with an optimization horizon of $15 \mathrm{~min}$. The discrete-state space model is established as (29) for the above parameters. (2) Based on the discrete-state space model and the forecasted wind-photovoltaic power load in the next $15 \mathrm{~min}$, whilst considering the operation constraints of the thermal power units, hydro-pumped storage units, and the battery in $5 \mathrm{~min}$ and the constraints of system power balance (as shown in formula (31)), the power correction of thermal units, hydro-pumped storage units, and the battery unit in the next $15 \mathrm{~min}$ is solved for the control variables sequences at time $t+1 \Delta t, t+2 \Delta t, t+3 \Delta t$. (3) Only the control variables in the first $5 \mathrm{~min}$ period are applied as the real-time corrective power. (4) Repeat the above procedures at time point $t+1 \Delta t$ to complete the real-time corrective scheduling.

The discrete space state model is as follows:

$$
X_{t+\Delta t}=\left[\begin{array}{c}
P_{g, i}(t+\Delta t) \\
P_{h, j}(t+\Delta t) \\
P_{b, l}(t+\Delta t) \\
W_{b, l}(t+\Delta t)
\end{array}\right]=\left[\begin{array}{cccc}
1 & 0 & 0 & 0 \\
0 & 1 & 0 & 0 \\
0 & 0 & 1 & 0 \\
0 & 0 & 1 & 1
\end{array}\right]\left[\begin{array}{c}
P_{g, i}(t) \\
P_{h, j}(t) \\
P_{b, l}(t) \\
W_{b, l}(t)
\end{array}\right]+\left[\begin{array}{ccc}
1 & 0 & 0 \\
0 & 1 & 0 \\
0 & 0 & 1 \\
0 & 0 & 1
\end{array}\right]\left[\begin{array}{c}
\Delta P_{g, i}(t) \\
\Delta P_{h, j}(t) \\
\Delta P_{b, l}(t)
\end{array}\right]
$$

where $i \in N G$ is the index of thermal power units; $j \in N H$ is the index of hydro-pumped storage units; $l \in N B$ is the index of batteries. Taking the state variable $X_{t 0}$ at the current time of $t 0$ as the initial value, the discrete-state space model is iterated three times to obtain the state variable for the $15 \mathrm{~min}$ time period with a time resolution of $5 \mathrm{~min}$. The MPC-based real-time corrective scheduling model is detailed in the following.

(1) Objective function

Because day-ahead and hour-level scheduling basically guarantee the power generation economy of thermal power generators and pumped storage units, real-time corrective scheduling needs to correct the power output of thermal power units, pumped storage units and batteries in the presence of prediction errors, and ensure the total power output of the whole combined WPTHB system is accurately tracking prediction errors and that it reduces power regulation cost by (30).

$$
\min Y=\sum_{\tau=1}^{P}\left[\left(X_{t 0+\tau \Delta t}^{r}-X_{t 0+\tau \Delta t}\right) W\left(X_{t 0+\tau \Delta t}^{r}-X_{t 0+\tau \Delta t}\right)^{T}+\Delta U_{t 0+\tau \Delta t} Q_{u} \Delta U_{t 0+\tau \Delta t}^{T}\right],
$$

where $W$ and $Q_{u}$ are the coefficient matrices; $t_{0}$ is the current time; $\Delta t$ is 5 min; $P$ is the number of prediction steps. Since the prediction time period is set to $15 \mathrm{~min}$ and the updated period is $5 \mathrm{~min}$, so $P=3$ here; $X_{t+\tau \Delta t}^{r}$ is the reference trajectory and $X_{t 0+\tau \Delta t}^{r}=\left[P_{g, i}^{\text {hours }, 0}(t 0+\tau \Delta t), P_{h, j}^{\text {hours }, 0}(t 0+\tau \Delta t), P_{b, 1}^{\text {day }}(t 0+\tau \Delta t) W_{b, 1}^{d a y}(t 0+\tau \Delta t)\right], i \in$ $N G, j \in N H, l \in N B ; X_{t 0+\tau \Delta t}$ is state variable at the time $t 0+\tau \Delta t ; X_{t 0+\tau \Delta t}=$ $\left[P_{g, \mathrm{i}}(t 0+\tau \Delta t), P_{h, \mathrm{j}}(t 0+\tau \Delta t), P_{b, 1}(t 0+\tau \Delta t), W_{b, 1}(t 0+\tau \Delta t)\right], i \in N G, j \in N H, l \in N B ; \Delta U_{t 0+\tau \Delta t}$ is the power adjustments of thermal power units, hydro-pumped storage units, and batteries, $\Delta U_{t 0+\tau \Delta t}=$ $\left[\Delta P_{g, i}(t 0+\tau \Delta t), \Delta P_{h, j}(t 0+\tau \Delta t), \Delta P_{b, 1}(t 0+\tau \Delta t)\right], i \in N G, j \in N H, l \in N B$. 
(2) Constraints

$$
\left\{\begin{array}{l}
\Delta P_{g, i}^{\min } \leq \Delta P_{g, i}(t+\tau \Delta t) \leq \Delta P_{g, i}^{\max } \\
P_{g, i}^{\min } \leq P_{g, i}(t+\tau \Delta t) \leq P_{g, i}^{\max } \\
\Delta P_{h, j}^{\min } \leq \Delta P_{h, j}(t+\tau \Delta t) \leq \Delta P_{h, j}^{\max } \\
P_{h, j}^{\min } \leq P_{h, j}(t+\tau \Delta t) \leq P_{h, j}^{\max } \\
\Delta P_{b, l}^{\min } \leq \Delta P_{b, l}(t+\tau \Delta t) \leq \Delta P_{b, l}^{\max } \\
P_{b, l}^{\min } \leq P_{b, l}(t+\tau \Delta t) \leq P_{b, l}^{\max } \\
W_{b, l}^{\min } \leq W_{b, l}(t+\tau \Delta t) \leq W_{b, l}^{\max } \\
\Delta P_{m, w}(t+\tau \Delta t)+\Delta P_{m, v}(t+\tau \Delta t)+\sum_{i=1}^{N G} \Delta P_{g, i}(t+\tau \Delta t)+\sum_{j=1}^{N H} \Delta P_{h, j}(t+\tau \Delta t)+\sum_{l=1}^{N B} \Delta P_{b, l}(t+\tau \Delta t)=\Delta P_{m, L o a d}(t+\tau \Delta t)
\end{array}\right.
$$

where $\Delta P_{g, i}^{\min }, \Delta P_{g, i}^{\max }, \Delta P_{h, j}^{\min }, \Delta P_{h, j}^{\max }, \Delta P_{b, l}^{\min }, \Delta P_{b, l}^{\max }$ are, respectively, the upper and lower limits of the allowable power adjustment of thermal power generators, hydro-pumped storage units, and batteries. $\Delta P_{m, w}(t+\tau \Delta t), \Delta P_{m, v}(t+\tau \Delta t), \Delta P_{m, \text { Load }}(t+\tau \Delta t)$ are, respectively, the forecast data of wind power, photovoltaic power, and load demand at the time $t 0+\tau \Delta t$.

\section{Case Studies}

\subsection{Parameters Setting}

A multi-energy complementary demonstration park in Guizhou is used to test the proposed model. As shown in Figure 2, the park is a nine-node system consisting of a wind farm, a photovoltaic plant, a hydro-pumped storage station, three thermal power generators, and two batteries. The hydro-pumped storage station has three pumped storage units, and the rated power and capacity of each unit are $50 \mathrm{MW}$ and $950 \mathrm{MW} \cdot \mathrm{h}$, respectively. The rated power and capacity of each battery is $25 \mathrm{MW}$ and $105 \mathrm{MW} \cdot \mathrm{h}$, respectively. Parameters of thermal power units are shown in Table $1(a, b$, and $c$ are the fuel cost coefficients of (2) cited from [24]). The actual and forecasted multi-time-scale wind-photovoltaic power load demand are given in Figure 3. Specifically, Figure 3a completely presents the day-ahead forecasted load demand (DFLD) with an hourly resolution, the short-term forecasted load demand (SFLD) with a 15-min resolution, the ultra-short-term forecasted load demand (UFLD) with a 5-min resolution, and the actual load demand (ALD) at nodes 5, 7, and 9, respectively; Figure 3b shows the day-ahead, the short-term, the ultra-short-term forecasted, and actual wind power at node 7, while Figure $3 c$ gives the day-ahead, the short-term, the ultra-short-term forecasted, and actual photovoltaic power at node 9 .

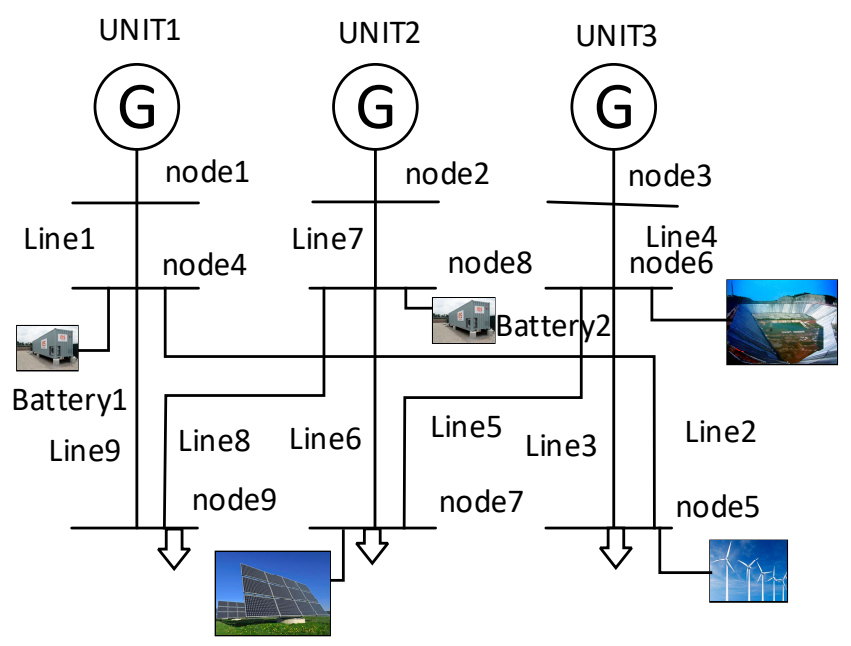

Figure 2. Wind-photovoltaic-thermal power generator, hydro-pumped storage, and battery combined system. 
Table 1. Thermal power generator parameters.

\begin{tabular}{|c|c|c|c|c|c|c|c|c|c|}
\hline \multirow{2}{*}{$\begin{array}{c}\text { Generator } \\
\text { No }\end{array}$} & \multirow{2}{*}{$\begin{array}{l}\text { Maximum } \\
\text { Power } \\
\text { (MW) }\end{array}$} & \multirow{2}{*}{$\begin{array}{l}\text { Minimum } \\
\text { Power } \\
\text { (MW) }\end{array}$} & \multicolumn{3}{|c|}{ Cost Coefficient } & \multirow{2}{*}{$\begin{array}{c}\text { Start } \\
\text { Cost }(\$)\end{array}$} & \multirow{2}{*}{$\begin{array}{l}\text { Down } \\
\text { Cost }(\$)\end{array}$} & \multirow{2}{*}{$\begin{array}{l}\text { Minimum } \\
\text { on Time (h) }\end{array}$} & \multirow{2}{*}{$\begin{array}{l}\text { Minimum } \\
\text { off Time (h) }\end{array}$} \\
\hline & & & $\begin{array}{c}a \\
\left(\$ / \mathbf{M W}^{2}\right)\end{array}$ & $\begin{array}{c}b \\
(\$ / M W)\end{array}$ & $c(\$)$ & & & & \\
\hline 1 & 350 & 10 & 0.11 & 5 & 150 & 1500 & 0 & 1 & 1 \\
\hline 2 & 500 & 10 & 0.085 & 1.2 & 600 & 2000 & 0 & 2 & 2 \\
\hline 3 & 400 & 10 & 0.1225 & 1 & 335 & 3000 & 0 & 2 & 2 \\
\hline
\end{tabular}

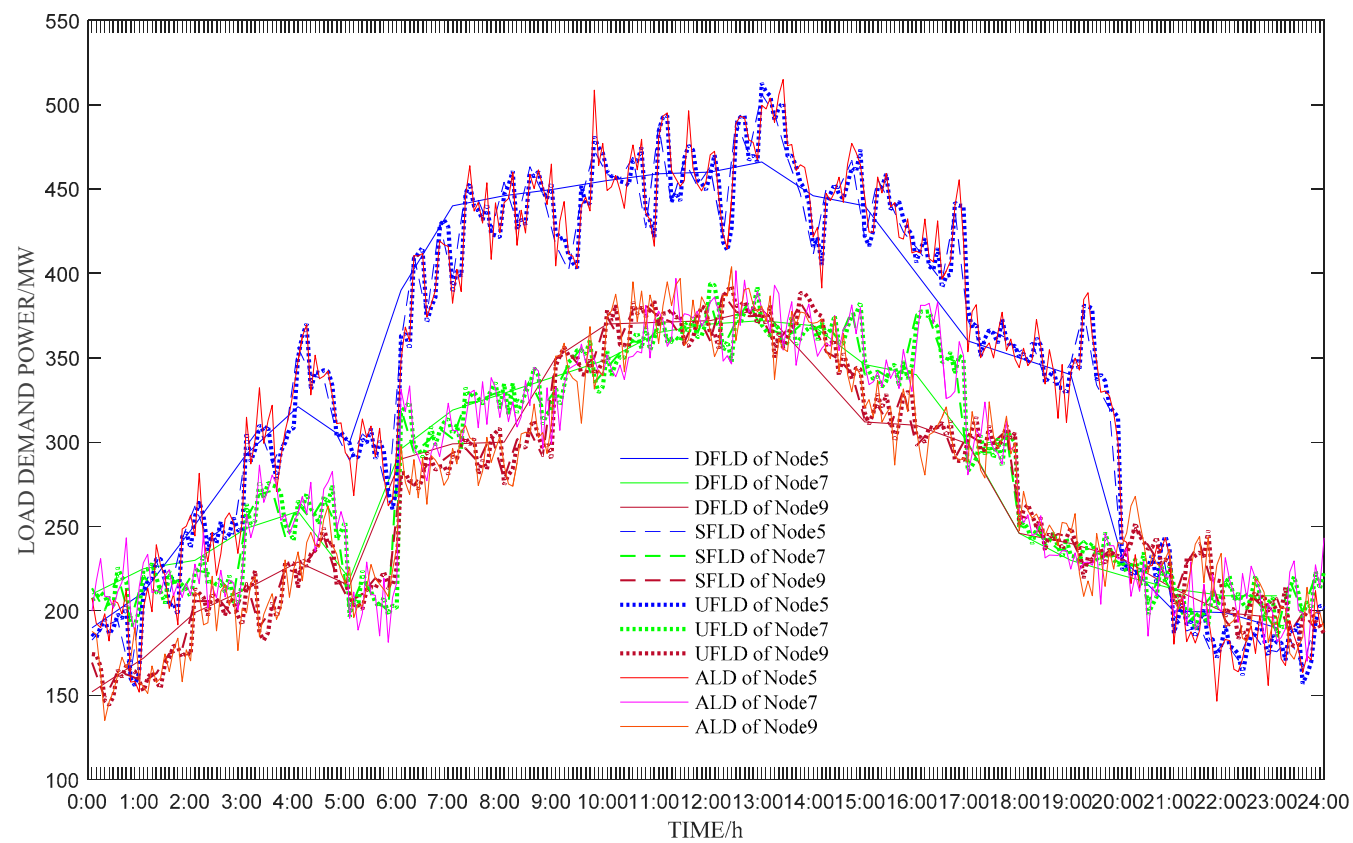

(a) Actual and forecast load demands in multi-time scales at nodes 5, 7, and 9 .

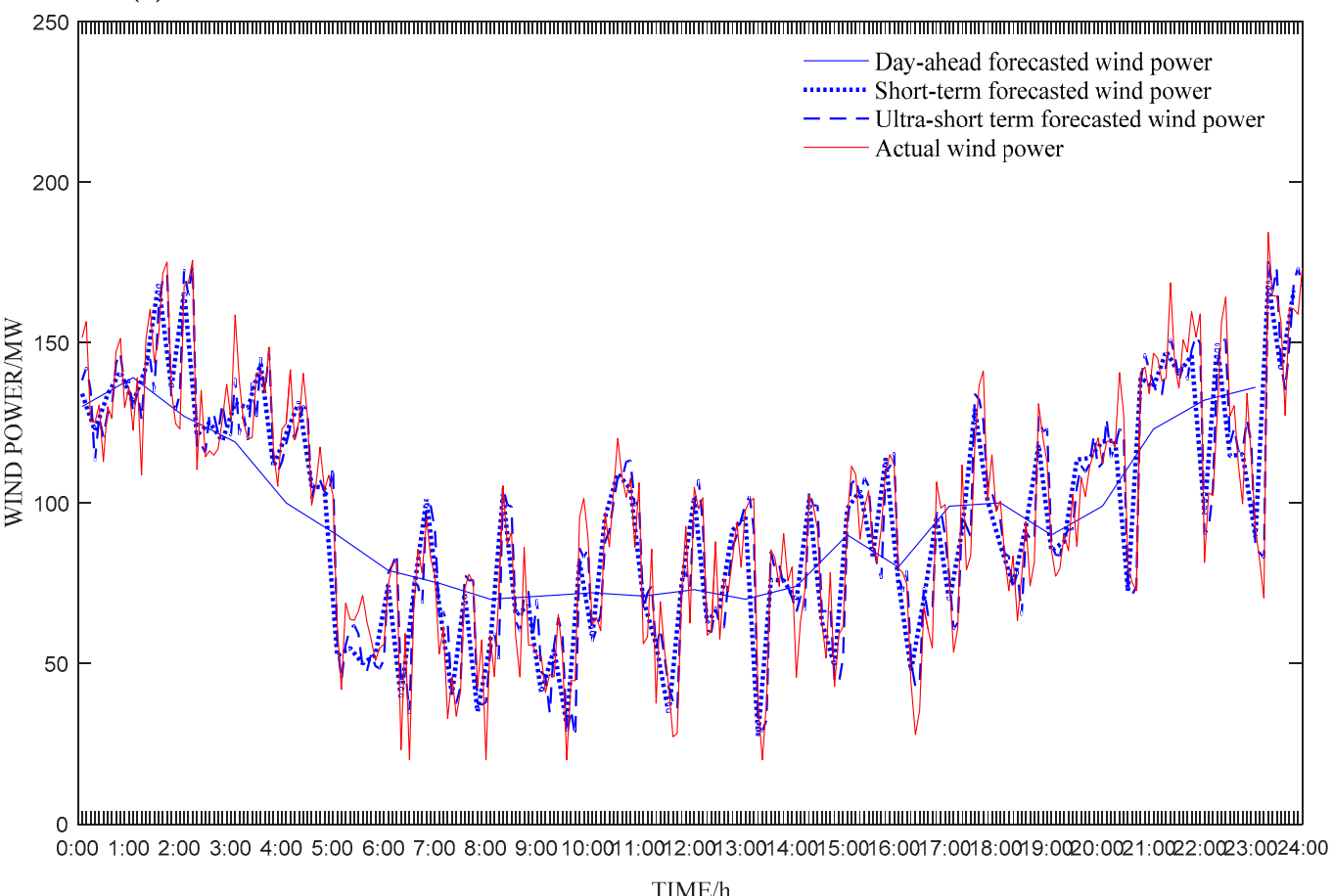

(b) Actual and forecasted wind power in multi-time scales at node 5.

Figure 3. Cont. 


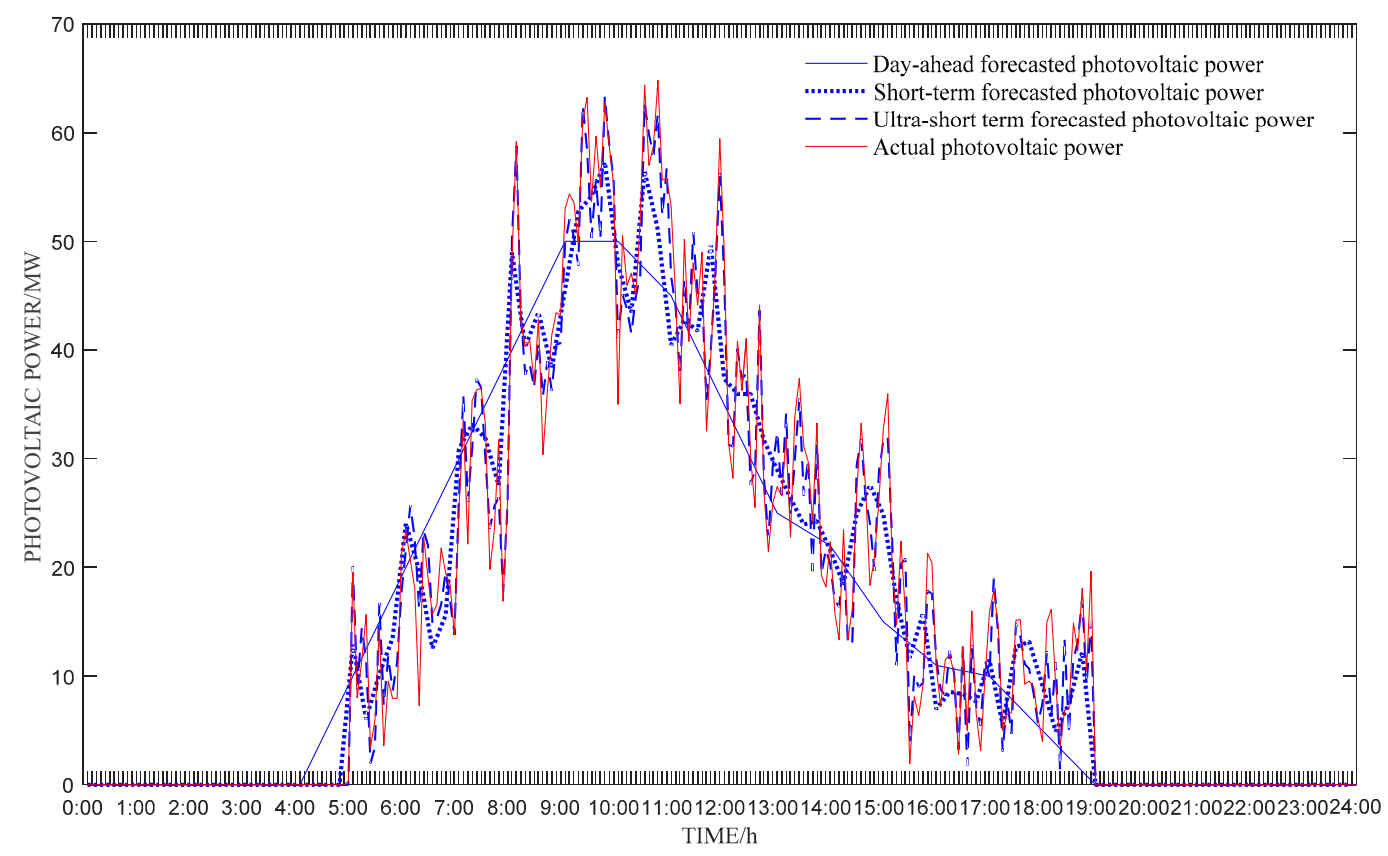

(c) Actual and forecasted photovoltaic power in multi-time scales at node 7.

Figure 3. Actual and forecasted wind-photovoltaic power load demand in multi-time scales.

\subsection{Simulation Results and Discussions}

The proposed multi-time-scale coordinated scheduling model is essentially a MILP optimization problem, and it is solved by the CPLEX tool developed by IBM(International Business Machines) Corporation as a high-performance mathematical programming solver [25].

a. Discussion on the day-ahead scheduling results

The day-ahead scheduling results of the WPTBH are shown in Figure 4. In the time periods of 0:00-5:00 and 22:00-24:00, the hydro-pumped storage units and the batteries have charged electrical energy during off-peak load periods. In the peak load hours from 9:00 to 18:00, the hydro-pumped storage units and the batteries release electrical energy, which helps to maintain a stable active power output of thermal power units during the peak and off-peak hours. It can be clearly seen that the day-ahead scheduling plan has a good peak-shaving and valley-filling performance due to hydro-pumped storage units and batteries, and they can reduce the climbing-up or down frequency of thermal power units. Additionally, as demonstrated in Figure $4 b, c$, both the reservoir energy of the hydro-pumped storage station consisting of three units and the batteries at the beginning of the day are exactly the same as the energy reservoir at the end of the day. This means that the proposed model has guaranteed the continuous operation of hydro-pumped storage units and batteries on the next day. 


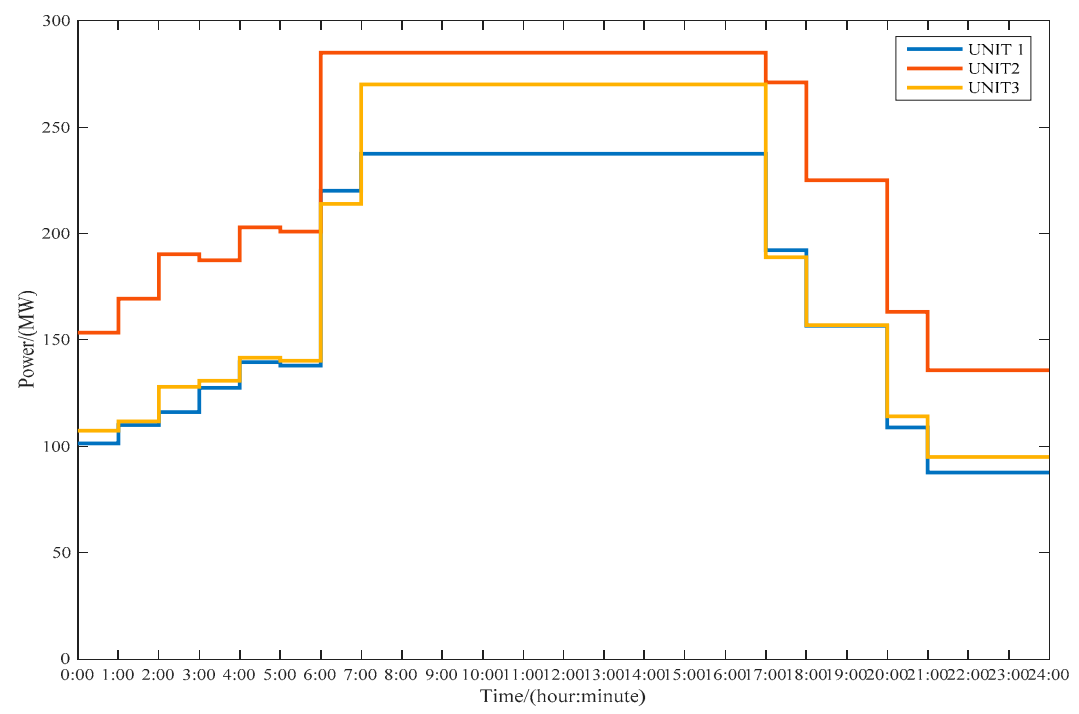

(a) Day-ahead active power outputs of thermal power units.

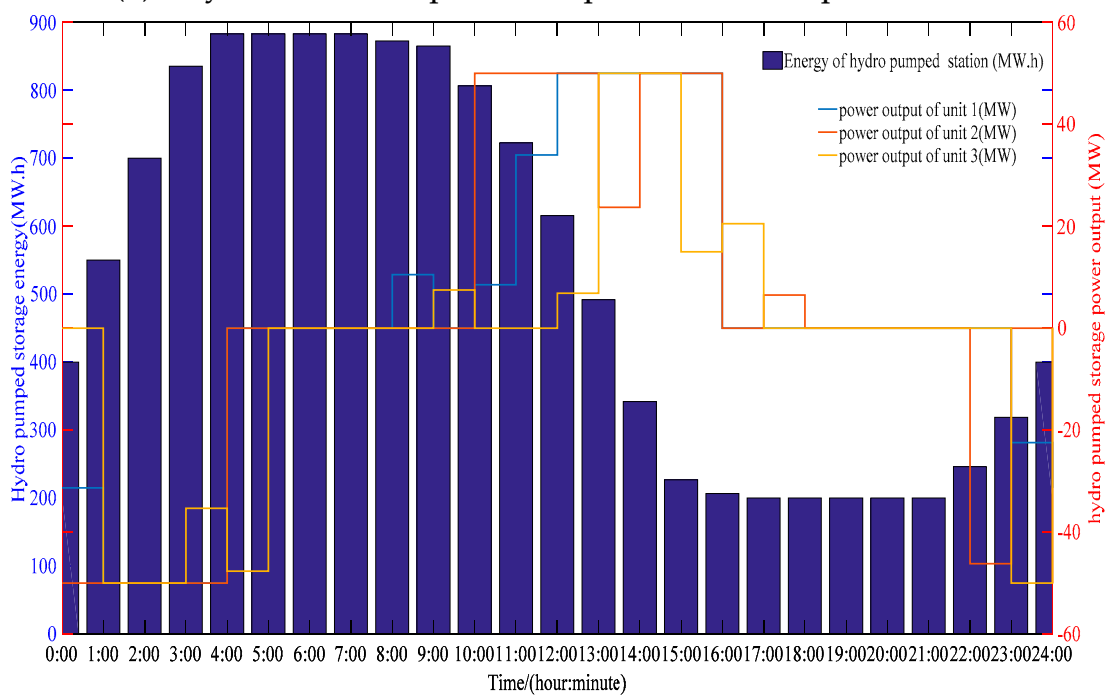

(b) Day-ahead active power outputs and energy reservoir of hydro-pumped storage units.

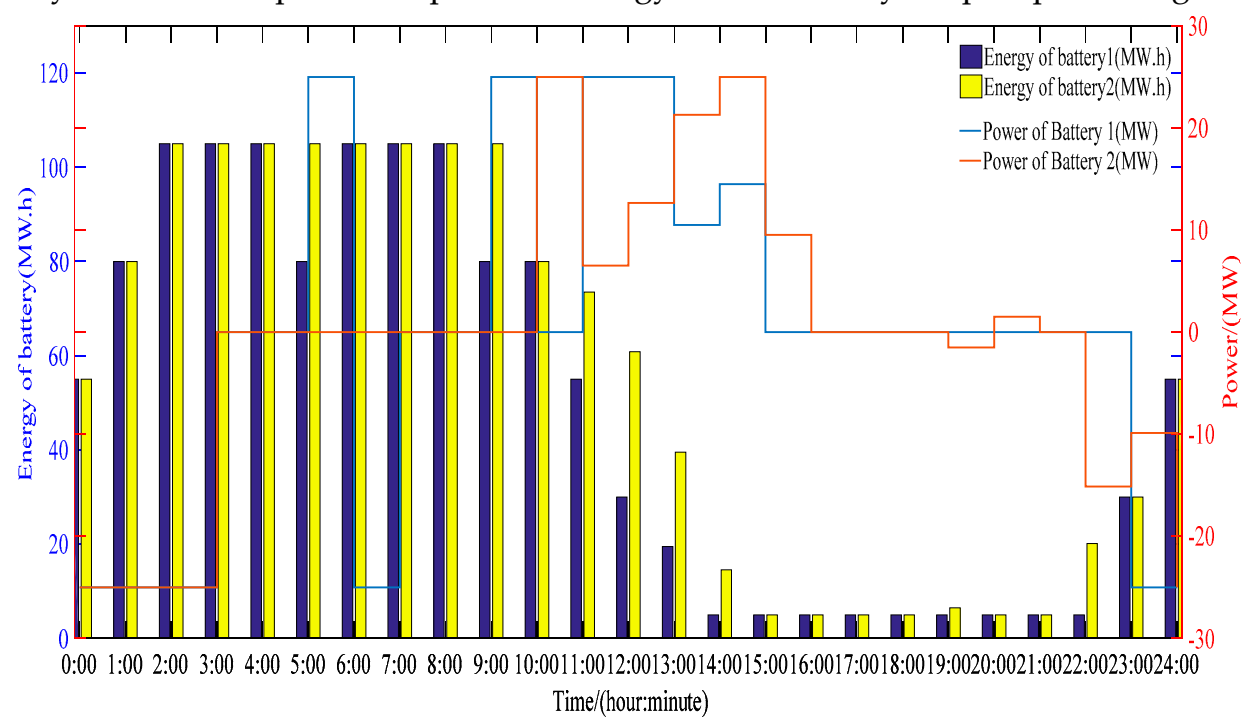

(c) Day-ahead active power outputs and energy of batteries.

Figure 4. Day-ahead power generation plan. 
b. Discussion on hour-level rolling corrective scheduling results

The hour-level rolling corrective scheduling model is conducted for the next $3 \mathrm{~h}$ with an interval of $15 \mathrm{~min}$. The corrected power outputs of hydro-pumped storage units and thermal power generators are shown in Figure 5.

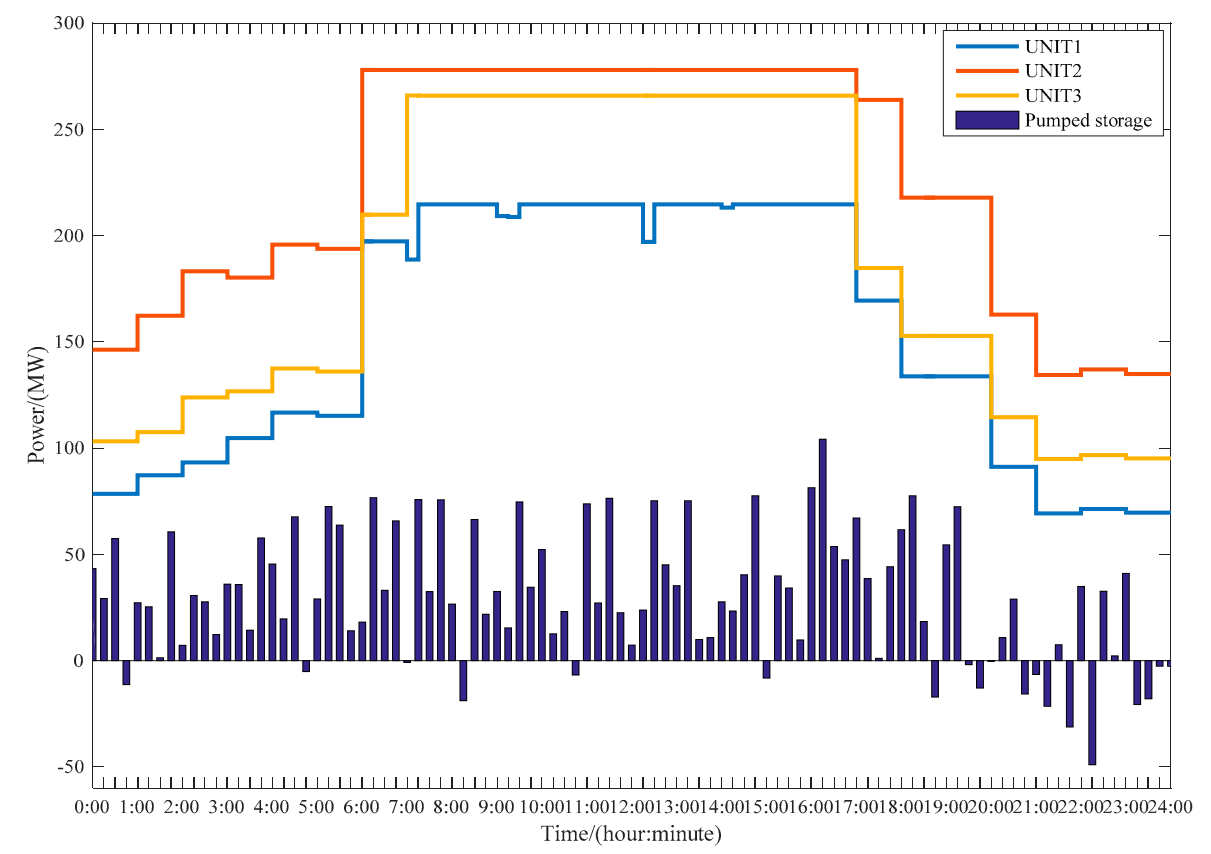

Figure 5. Active power outputs of thermal power generators and hydro-pumped storage units under the hour-level rolling corrective scheduling.

It can be seen that the deviation of $3 \mathrm{~h}$ ahead forecasted wind-photovoltaic power load with regard to the day-ahead forecasted wind-photovoltaic power load was well balanced in the hour-level rolling corrective schedule by hydro-pumped storage units. In specific, hydro-pumped storage units rapidly adjust the charging and discharging power to bear the fast-fluctuated wind-photovoltaic power load, while the thermal power units bear the slowly-changed load. The proposed hour-level rolling corrective scheduling model fully takes advantages of the fast power-regulation speed of the hydro-pumped storage units to reduce the ramping-up and down pressure of thermal power units.

c. Discussion on the real-time corrective scheduling results

In the real-time correction stage, the $15 \mathrm{~min}$ ahead forecasted wind-photovoltaic power load is used to correct the power outputs of thermal power units, hydro-pumped storage units and batteries.

The corrective active power outputs of thermal power units, hydro-pumped storage units and batteries are presented in Figure 6. Both the hydro-pumped storage unit and the batteries can quickly adjust their active power outputs to alleviate the power output adjustment of thermal power units. The proposed real-time corrective scheduling model has fully explored the rapid power-adjustment capability of hydro-pumped storage unit and batteries to track the wind-photovoltaic power load fluctuation and thus well maintain system power balances in real-time.

The power deviation percentage is defined as the error of the total active power output of a scheduling plan benchmarked with the actual wind-photovoltaic power load. From the power deviation percentage comparisons of three time scales shown in Figure 7, the power deviation percentage of the day-ahead scheduling plan is the largest. When the hour-level rolling corrective schedule is further conducted as the supplementary of the day-ahead scheduling, the power deviation percentage is greatly reduced but still with large fluctuations. If the real-time corrective scheduling is further added to the hour-level rolling corrective schedule, resulting in the proposed integrated multi-time 
coordinated scheduling model, the power deviation percentage could be satisfactorily reduced, and the amplitude of total power-generation fluctuation is very small. The power deviation of day-ahead scheduling is large due to the very coarse day-ahead windphotovoltaic power and load prediction for the next $24 \mathrm{~h}$. When the forecast data is hourly updated to correct the active power output of day-ahead scheduling, the hour-level rolling corrective scheduling plan could greatly reduce the power deviation percentage. In the real-time corrective scheduling stage, $5 \mathrm{~min}$ resolution ultra-short-term forecasting data is used to get a further re-correction plan to effectively track the wind-photovoltaic power load.

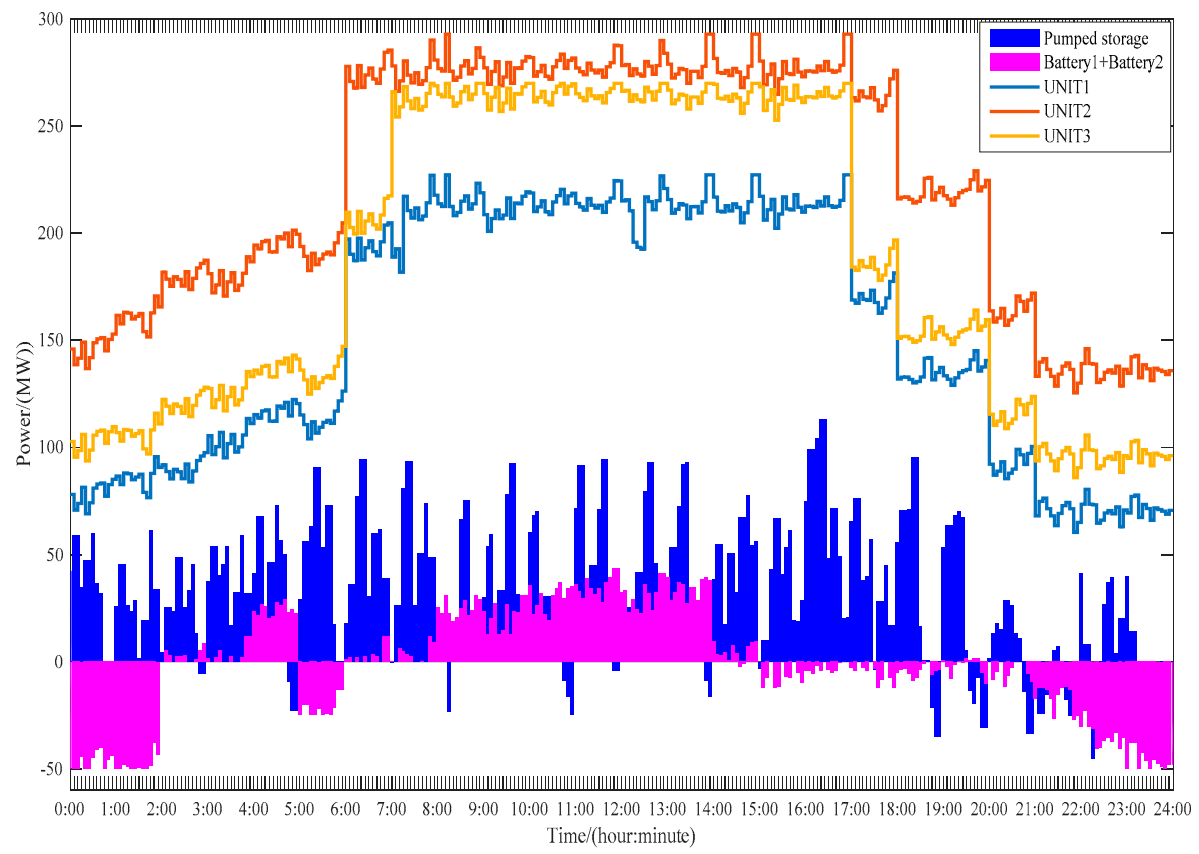

Figure 6. Active power output of thermal power unit, hydro-pumped storage unit, and batteries after applying the real-time corrective schedule.

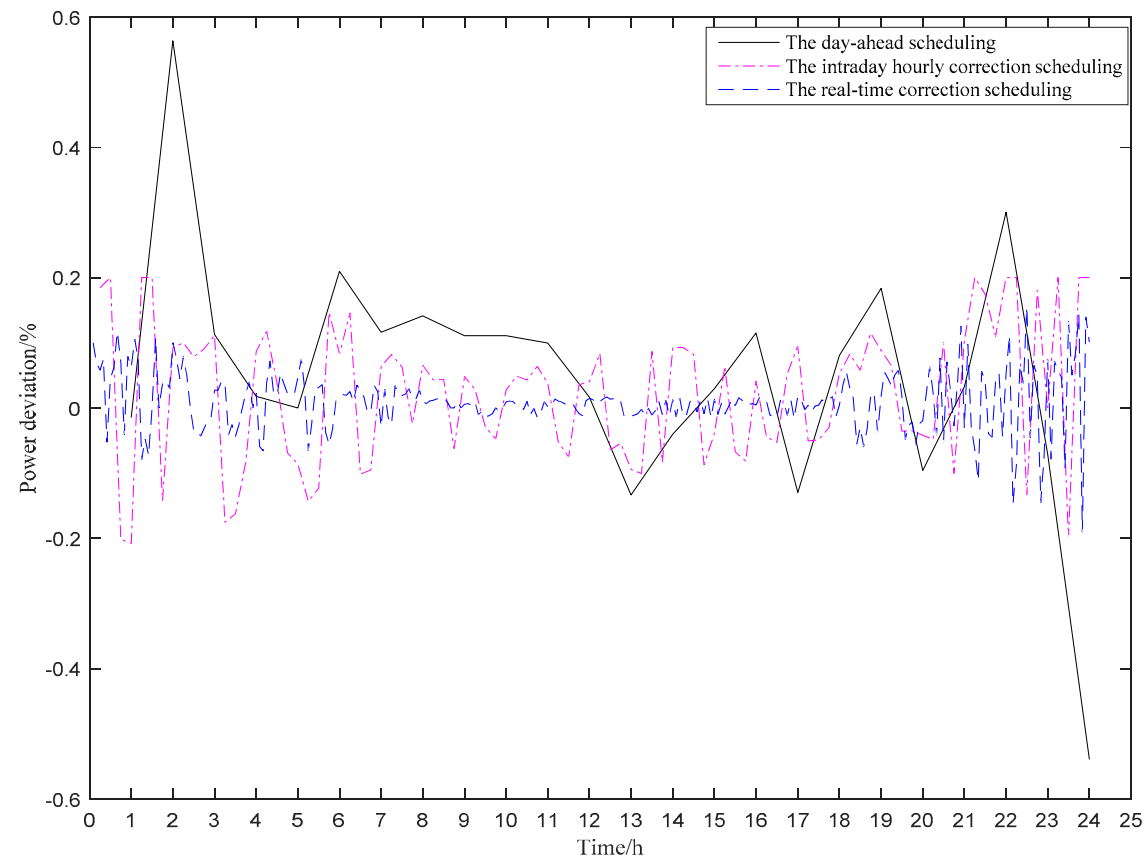

Figure 7. Power deviation percentage of three time-scale scheduling methods benchmarked with an actual system generalized load. 
d. Comparison of different scheduling schemes

In order to further illustrate the superiority of the proposed multi-time-scale coordinated scheduling model, two different scheduling models are compared as follows.

Scheme A: The proposed multi-time-scale active power coordinated scheduling model based on MPC for wind-photovoltaic-thermal power generator, hydro-pumped storage, and battery units.

Scheme B: The multi-time-scale active coordinated scheduling model based on the single time-section correction instead of MPC-based multiple time-section correction in the real-time corrective scheduling stage.

Scheme C: MPC-based multi-time-scale active power coordination scheduling for thermal generators, namely the scheme $\mathrm{C}$ considers only thermal power generators to balance wind-photovoltaic power fluctuations.

The load ratio of a transmission line is defined as the percentage of actual apparent power flow of the transmission line over its rated power capacity. Figure 8 shows the load ratio of all transmission lines in scheme A and B. As shown in Figure 8a-c, the load ratios of lines 1, 3, and 9 in scheme B are larger than 1 during the periods of 7:00-8:00, 10:00-11:00, and 20:00-21:00, which indicates that transmission lines 1,3, and 9 are overloaded and the static security of the power networks is threatened. However, the load ratio of all transmission lines in scheme A is maintained within a range fully less than 1, and thus the proposed scheme A could well maintain the network static security. At the same time, the fluctuation of load ratio amplitude of all transmission lines in scheme B is larger than that of scheme A. This is because the here proposed scheme A uses an MPC-based real-time correction strategy to consider the wind-photovoltaic power and load prediction for a time period in advance, and thus can timely sense the load demand changing trend in the coming time period compared with scheme B only for a single-time section. Therefore, scheme A can properly adjust the active power output of thermal power generators, hydro-pumped storage units, and battery units in advance to avoid the large fluctuations of transmission lines' power flow.

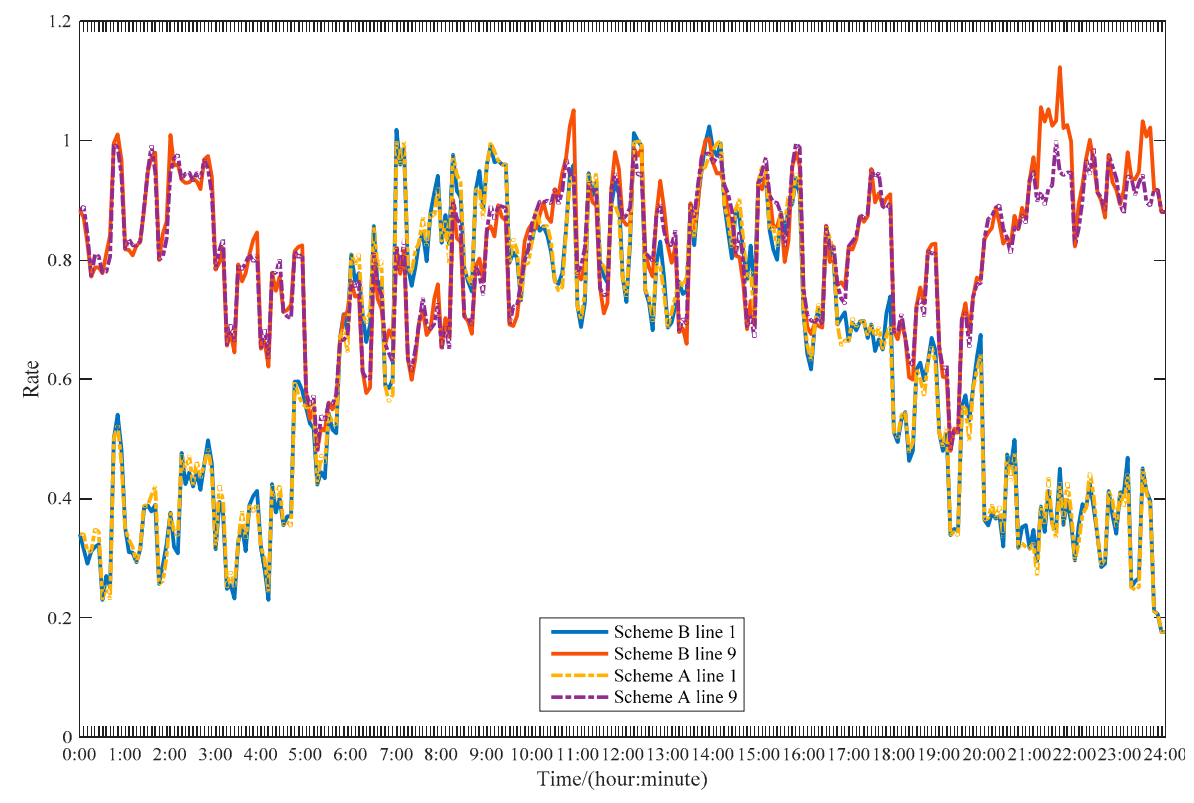

(a) Load ratio of transmission lines 1 and 9 in schemes A and B.

Figure 8. Cont. 


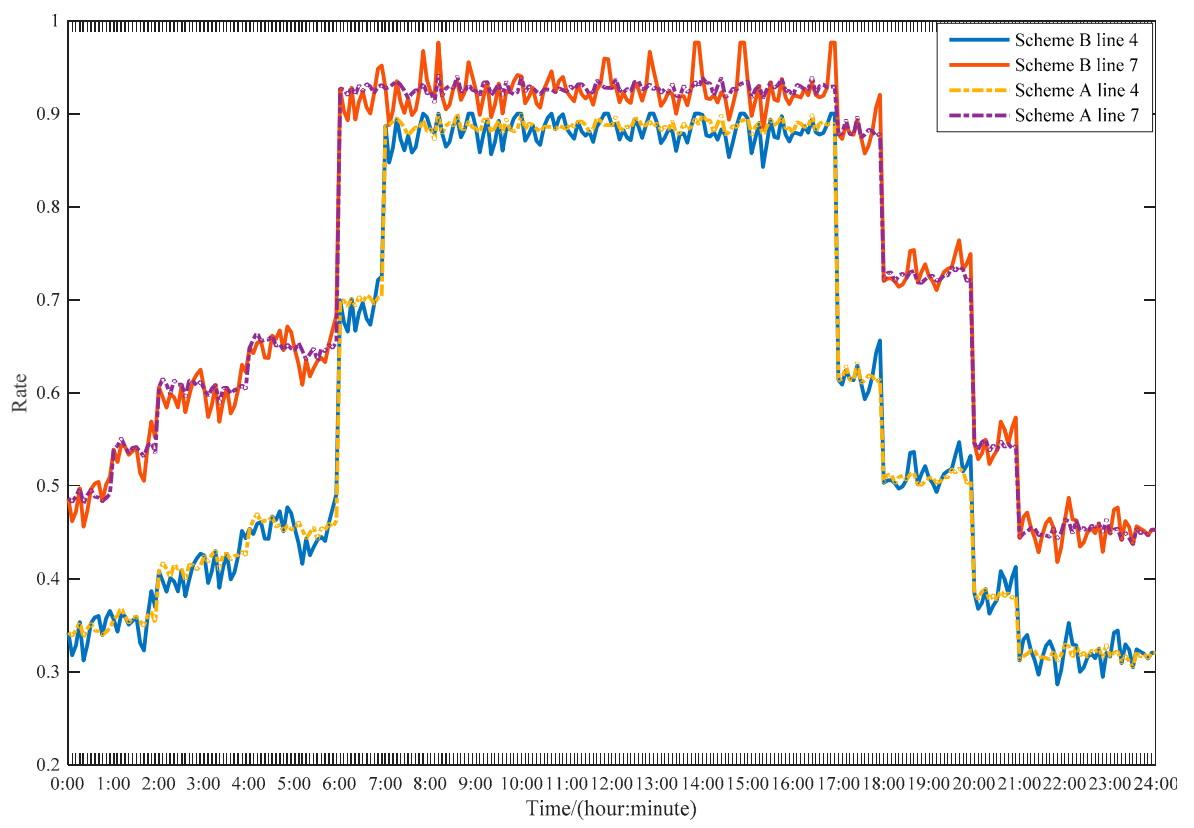

(b) Load ratio of transmission lines 4 and 7 in schemes A and B.

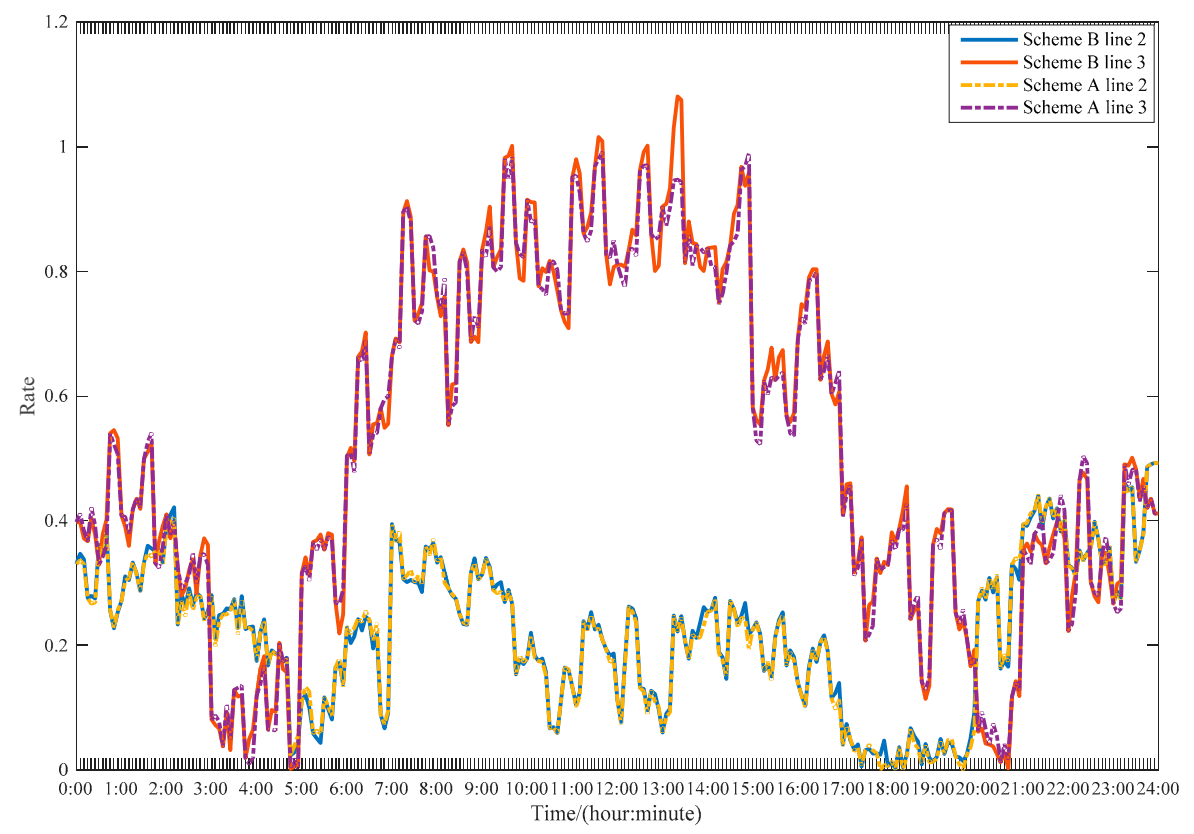

(c) Load ratio of transmission lines 2 and 3 in schemes A and B.

Figure 8. Cont. 


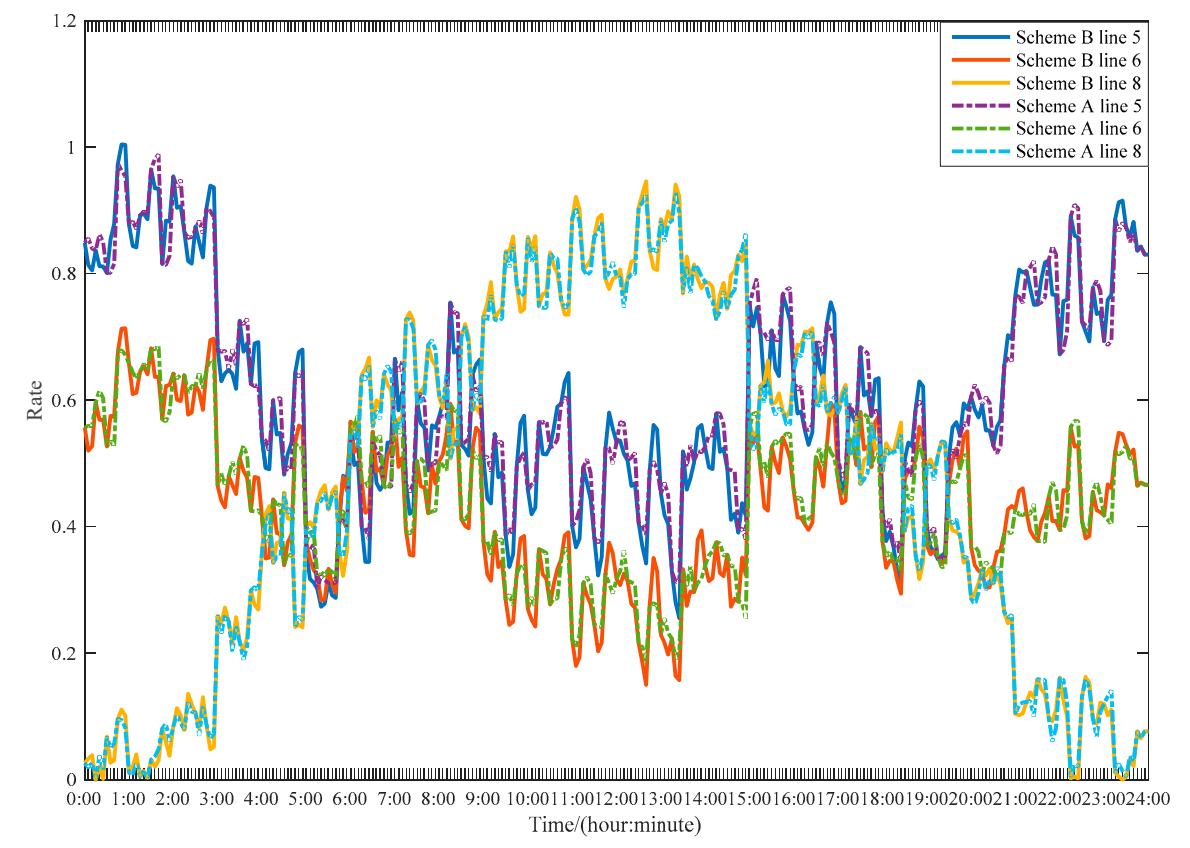

(d) Load ratio of transmission lines 5, 6, and 8 in schemes A and B.

Figure 8. Load ratio (line apparent power flow over rated capacity) of nine transmission lines in scheme A and B.

The comparison of scheme A with scheme C (Figures 9-11) clearly demonstrates that the active power outputs of thermal units in scheme $A$ are relatively smooth and their fluctuation magnitudes are small for all the three time-scale scheduling methods. That is because the proposed scheme A has the capability of energy shifting with the help of energy storage devices, such as the hydro-pumped storage units and batteries, the subject of this paper, which greatly reduces the ramp-up/down pressure of thermal power units. Furthermore, as shown in Table 2, the daily power generation cost of scheme A is $\$ 746,480$ ( $\$$ is for United States dollar.), which is $18 \%$ smaller than the $\$ 908,400$ cost of scheme $\mathrm{C}$, this mean that the proposed scheme A could greatly improve the operation economics of the combined system.

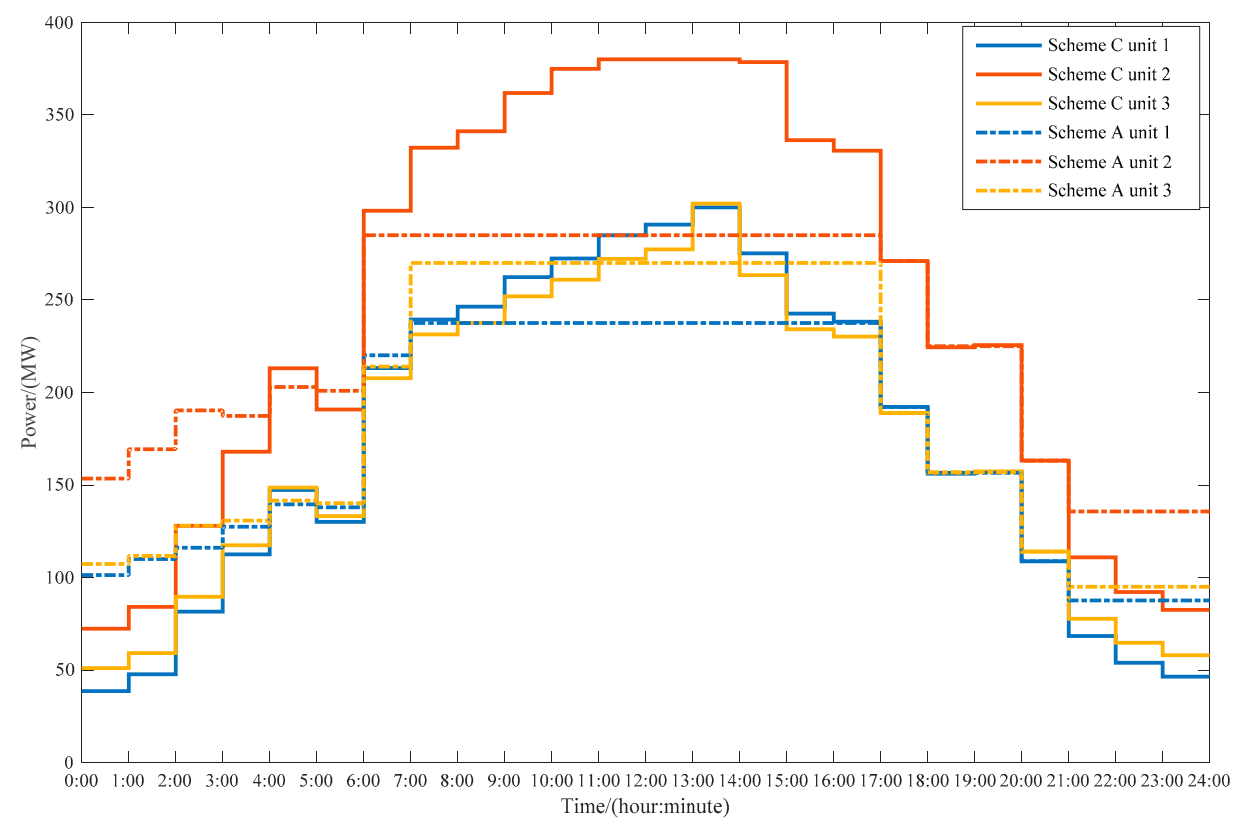

Figure 9. Thermal generator power outputs in the day-ahead scheduling of schemes A and C. 


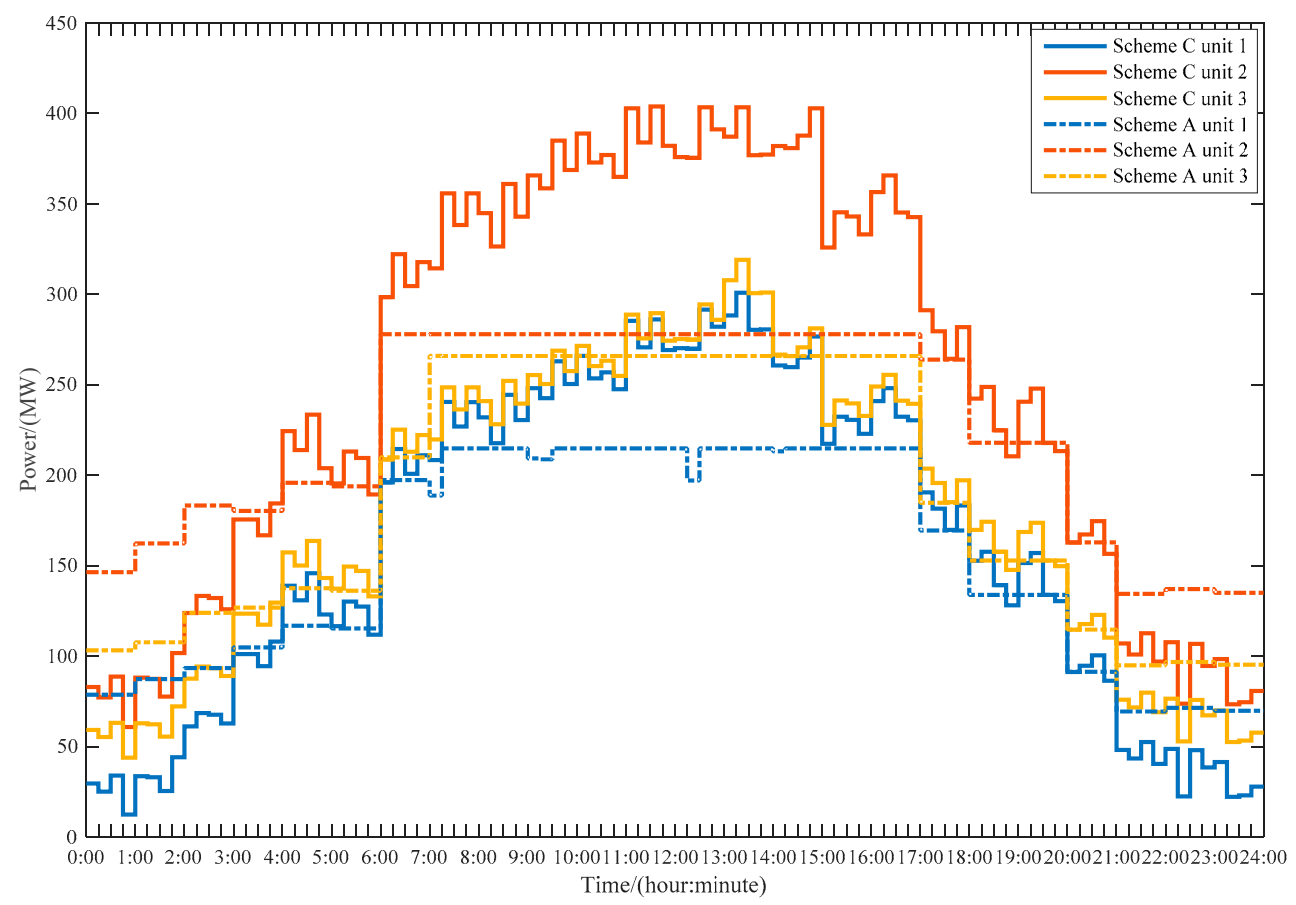

Figure 10. Thermal generator power outputs after applying the hour-level rolling correction scheduling of schemes A and C.

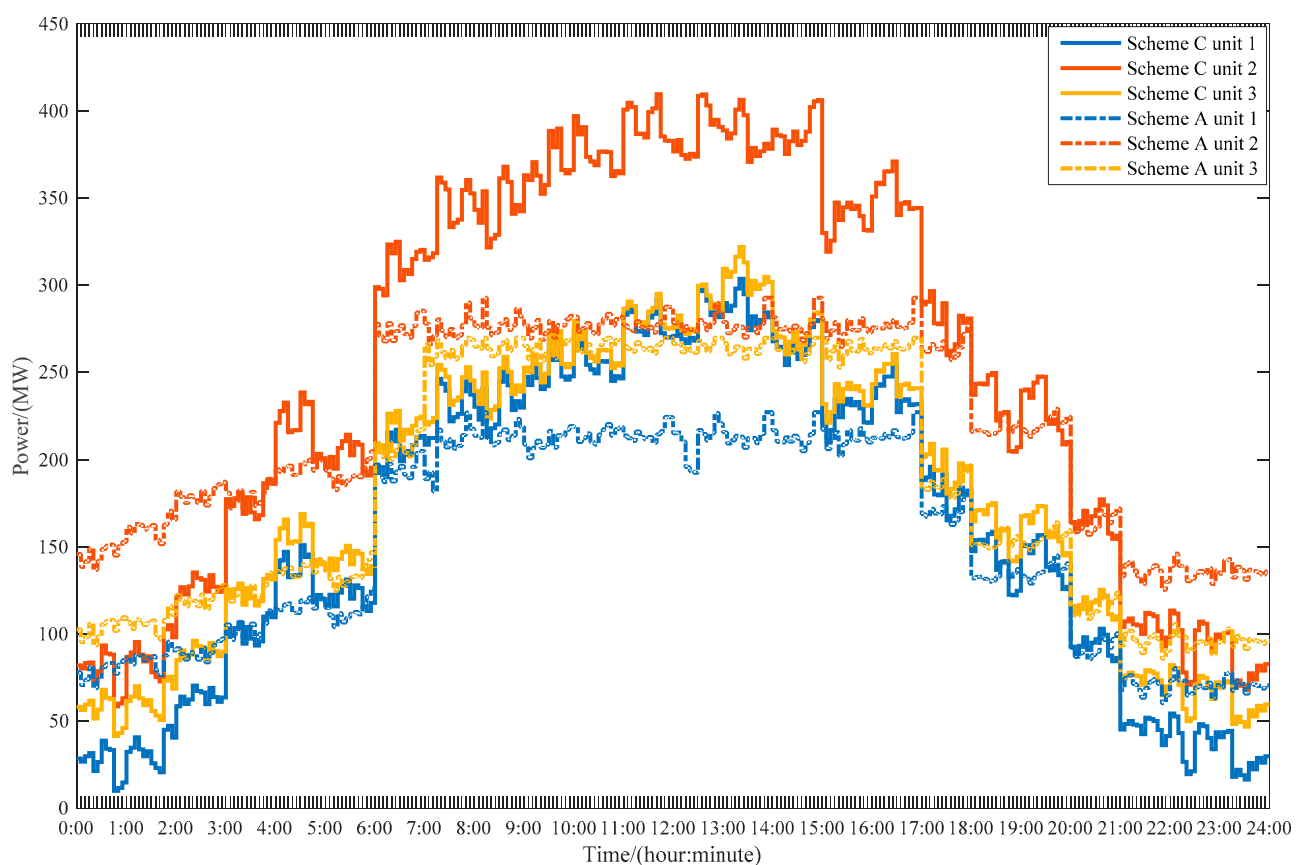

Figure 11. Thermal generator power outputs after applying real-time scheduling of schemes A and C.

Table 2. Power generation operating costs of schemes A and C.

\begin{tabular}{cc}
\hline Scheme No. & Power Generation Costs (\$) \\
\hline A & 746,480 \\
C & 908,400 \\
\hline
\end{tabular}




\section{Conclusions}

In this paper, a multi-time-scale active power coordinated scheduling model is proposed for combined operation of the wind-photovoltaic-thermal-hydro power and battery units. The proposed multi-time-scale scheduling model was established with three stages: day-ahead scheduling, hour-level rolling corrective schedule, and MPC-based real-time corrective scheduling. Based on the mutual coordination of three time-scale scheduling methods, the predicted error between the optimized system total power generation and the actual wind-photovoltaic power load demand can be corrected step-by-step using day-ahead scheduling, hour-level rolling corrective scheduling, and real-time corrective scheduling from long- to short-time scales. Simulation results of the demonstration park in Guizhou validated that the proposed multi-time-scale coordinated scheduling model could well explore the distinguished power regulation speeds and power regulation capacity of thermal power units, hydro-pumped storage units, and batteries in different time scales, and; therefore, it can improve the economic operation and static security of combined systems.

Author Contributions: Conceptualization, D.Z., S.X. and T.D.; methodology, D.Z., S.X. and T.D.; software, T.D.; validation, T.D.; writing-original draft preparation, D.Z., T.D., H.Y., S.X. and H.Z.; writing-review and editing, S.X. and T.D.

Funding: This work was funded in part by the Jiangsu Basic Research Project (Natural Science Foundation BK20180284), in part by The Smart Grid Joint Foundation Program of National Natural Science Foundation of China and State Grid Corporation of China (U1866204), and the Fundamental Research Funds for the Central Universities (2019MS007).

Conflicts of Interest: The authors declare no conflict of interest.

\section{References}

1. Awadallah, M.A.; Venkatesh, B. Energy Storage in Distribution System Planning and Operation: Current Status and Outstanding Challenges. J. Can. J. Electr. Comput. Eng. 2019, 42, 10-19.

2. Nazariheris, M.; Abapour, S.; Mohammadiivatloo, B. Optimal economic dispatch of FC-CHP based heat and power micro-grids. J. Appl. Therm. Eng. 2019, 114, 756-769. [CrossRef]

3. Tsai, S.B. Using grey models for forecasting China's growth trends in renewable energy consumption. J. Clean Technol. Environ. Policy 2016, 18, 563-571. [CrossRef]

4. Jin, X.; Mu, Y.; Jia, H.; Wu, J.; Jiang, T.; Yu, X. Dynamic economic dispatch of a hybrid energy microgrid considering building based virtual energy storage system. J. Appl. Energy 2016, 194, 386-398. [CrossRef]

5. Ran, W.; Ping, W.; Xiao, G.; Gong, S. Power demand and supply management in microgrids with uncertainties of renewable energies. J. Int. J. Electr. Power Energy Syst. 2014, 63, 260-269.

6. Qian, A.; Ran, H. Key Technologies and Challenges for Multi-energy Complementarity and Optimization of Integrated Energy System. J. Autom. Electr. Power Syst. 2018, 42, 2-10.

7. Xiao, Q.Z.; Qian, A.; Lin, L.; Shuai, Y. Multi-energy complementary microgrid cluster distributed optimization scheduling. J. Power Grid Technol. 2019, 5, 1-9.

8. Yuan, L.S.; Qian, A.; Jian, P.Z.; Ren, B.W. Two-level coordination mechanism and operation strategy of multi-virtual power plants with multiple time scales. J. Chin. Soc. Electr. Eng. 1994, 38, 753-761.

9. Zheng, N.W.; Ji, C.L. Optimized scheduling method for linkage of wind and water complementary power generation system and demand side data center. J. Power Grid Technol. 2019, 5, 1-13.

10. Si, Q.S.; Li, Z. Economic dispatching of power system based on multi-energy complementation of scenery, water and fire. J. Electr. Meas. Instrum. 2016, 53, 66-71.

11. Yue, C.; Feng, L.; Wei, W.; Sheng, W.M.; Nai, C.C. Robust unit commitment for large-scale wind generation and run-off-river hydropower. J. Chin. Soc. Electr. Eng. J. Power Energy Syst. 2016, 2, 66-75.

12. Komiyama, R.; Fujii, Y. Assessment of Japan's Optimal Power Generation Mix Considering Massive Deployment of Variable Renewable Power Generation. J. Electr. Eng. Jpn. 2013, 2, 1-11. [CrossRef]

13. Xin, H.X.; Zong, H.G.; Heng, Q.L.; Fan, X.; Gang, W. Combined optimization scheduling of scenery, water, fire and multi-energy bases considering space-time complementary characteristics. J. Power Eng. Technol. $2017,36,59-65$. 
14. Kusakana, K. Optimal scheduled power flow for distributed photovoltaic/wind/diesel generators with battery storage system. J. IET Renew. Power Gener. 2015, 9, 916-924. [CrossRef]

15. Akram, U.; Khalid, M.; Shafiq, S. Optimal sizing of a wind/solar/battery hybrid grid-connected microgrid system. J. IET Renew. Power Gener. 2018, 12, 72-80. [CrossRef]

16. Bao, Z.; Zhou, Q.; Yang, Z.; Yang, Q.; Xu, L.; Wu, T. A Multi Time-Scale and Multi Energy-Type Coordinated Microgrid Scheduling Solution-Part I: Model and Methodology. J. IEEE Trans. Power Syst. 2015, 30, 2257-2266. [CrossRef]

17. Bukhsh, W.A.; Zhang, C.; Pinson, P. An Integrated Multiperiod OPF Model with Demand Response and Renewable Generation Uncertainty. J. IEEE Trans. Smart Grid 2015, 7, 1-9. [CrossRef]

18. $\mathrm{Xu}, \mathrm{T}$; Z Zhang, N. Coordinated Operation of Concentrated Solar Power and Wind Resources for the Provision of Energy and Reserve Services. J. IEEE Trans. Power Syst. 2016, 32, 1260-1271. [CrossRef]

19. Na, Z.; Quan, L.; Xian, Z.; Hai, X.W.; Wei, D.L. Multi-stage unit combination coordination strategy for wind power systems. J. Autom. Electr. Power Syst. 2013, 37, 39-45, 98.

20. Yang, H.; Wei, H.; Yong, M.; Wei, H.L.; Zhi, M.W.; Wei, C.G. Consider multi-objective coordinated scheduling of wind storage joint system planned in the day. J. Chin. Soc. Electr. Eng. 2014, 34, 4743-4751.

21. Hao, W.; Qian, A.; Lin, G.; Xiao, Q.Z.; Fan, H. Cooperative optimization of combined cooling and heating systems based on multi-scenario random programming and MPC. J. Autom. Electr. Power Syst. 2018, 42, 51-58.

22. Zhang, B.M.; Wu, W.C.; Zheng, T.Y.; Sun, H.B. Design of multi-time-scale coordinated active dispatching system for large-scale wind power consumption. J. Autom. Electr. Power Syst. 2011, 35, 1-6.

23. Xiao, F.; Ai, Q. Multi-time-scale demand response resource optimization scheduling of microgrid based on model predictive control. J. Power Autom. Equip. 2018, 38, 184-190.

24. Zimmerman, R.D.; Murillo-Sanchez, C.E.; Thomas, R.J. MATPOWER: Steady-State Operations, Planning, and Analysis Tools for Power Systems Research and Education. J. IEEE Trans. Power Syst. 2011, 26, 12-19. [CrossRef]

25. IBM. ILOG CPLEX Optimization Studio. 2013. Available online: http://www-01.ibm.com/software/ integration/optimization/cplexoptimization-studio/ (accessed on 21 August 2019).

(C) 2019 by the authors. Licensee MDPI, Basel, Switzerland. This article is an open access article distributed under the terms and conditions of the Creative Commons Attribution (CC BY) license (http://creativecommons.org/licenses/by/4.0/). 